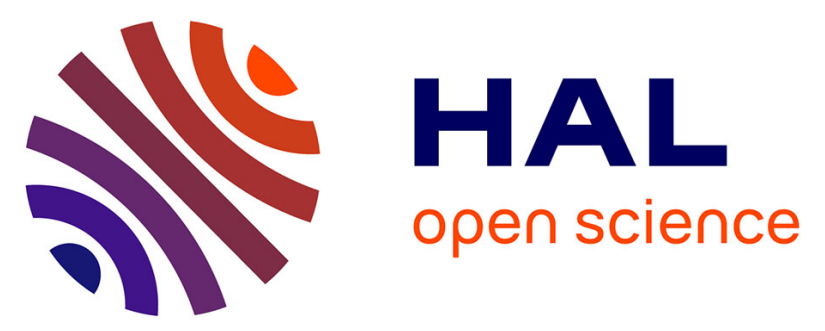

\title{
Synthesis and physic-chemical properties of a novel chromate compound with potential biological applications, bis(2-phenylethylammonium) chromate(VI)
}

S. Trabelsi, N. Issaoui, S.A. Brandán, F. Bardak, T. Roisnel, A. Atac, H. Marouani

\section{To cite this version:}

S. Trabelsi, N. Issaoui, S.A. Brandán, F. Bardak, T. Roisnel, et al.. Synthesis and physicchemical properties of a novel chromate compound with potential biological applications, bis(2phenylethylammonium) chromate(VI). Journal of Molecular Structure, 2019, 1185, pp.168-182. 10.1016/j.molstruc.2019.02.106 . hal-02090001

HAL Id: hal-02090001

https://hal-univ-rennes1.archives-ouvertes.fr/hal-02090001

Submitted on 17 Apr 2019

HAL is a multi-disciplinary open access archive for the deposit and dissemination of scientific research documents, whether they are published or not. The documents may come from teaching and research institutions in France or abroad, or from public or private research centers.
L'archive ouverte pluridisciplinaire HAL, est destinée au dépôt et à la diffusion de documents scientifiques de niveau recherche, publiés ou non, émanant des établissements d'enseignement et de recherche français ou étrangers, des laboratoires publics ou privés. 

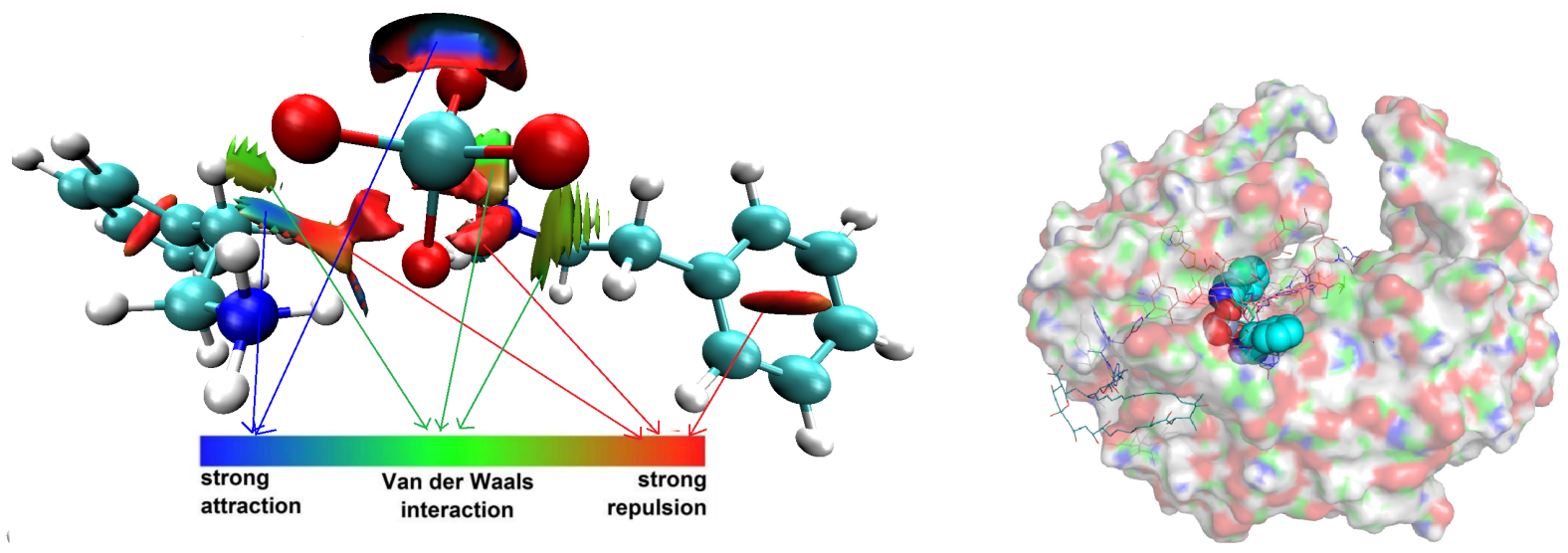


\title{
Synthesis and physic-chemical properties of a novel chromate compound with potential biological applications, bis(2-phenylethylammonium) chromate(VI)
}

Sonia Trabelsi ${ }^{\mathrm{a}}$, Noureddine Issaoui ${ }^{\mathrm{b}}$, Silvia A. Brandán ${ }^{\mathrm{c}},{\text { Fehmi } \text { Bardak }^{\mathrm{d}} \text {, Thierry Roisnel }}^{\mathrm{e}}$, Ahmet Atac $^{\mathrm{d}}$, Houda Marouani ${ }^{\mathrm{a}}$

(a) Laboratoire de Chimie des Matériaux, Faculté des Sciences de Bizerte, Université de Carthage, 7021

\section{Zarzouna,Tunisia}

(b) Laboratory of Quantum and Statistical Physics, Faculty of Sciences, University of Monastir, Monastir 5079, Tunisia

(c)Cátedra de Química General. Instituto de Química Inorgánica. Facultad de Bioquímica, Química y

Farmacia. Universidad Nacional de Tucumán. Ayacucho 471. 4000. San Miguel de Tucumán. Tucumán. R. Argentina.

(d) Department of Physics, Celal Bayar University, Manisa, Turkey.

(e) Centre de Diffractométrie X, UMR 6226 CNRS, Unité Sciences Chimiques de Rennes, Université de Rennes I, 263 Avenue du Général Leclerc, 35042 Rennes, France

\begin{abstract}
The structure of bis(2-phenylethylammonium) chromate(VI) (2phCr ) was determined from $\mathrm{X}$-ray diffraction data. The compound crystallizes in the monoclinic system (space group C2/c) with the lattice parameters: $\mathrm{a}=38.136(2) \AA, \mathrm{b}=11.2334(6) \AA$, c = 8.1643(4) $\AA$; $\beta=$ 98.480(2) $\mathrm{V}=3459.3(3) \AA^{3}$ and $\mathrm{Z}=8$. The structure was solved from 3358 independent reflections with $\mathrm{R}=0.034$ and $\mathrm{Rw}=0.1089$. The structure consists of discrete anions $\left(\mathrm{CrO}_{4}{ }^{2-}\right)$ stacked in layers parallel to (b, c) plane at $\mathrm{x}=1 / 4$ and 3/4. These anions are connected to the 2-phenylethylammonium cations through $\mathrm{N}-\mathrm{H}$...O and C-H...O hydrogen bonds, forming a two-dimensional arrangement. Crystal structure and spectroscopic studies are reported for the 2phCr. In addition, Hirshfeld surfaces and two-dimensional fingerprint plots estimate the intermolecular interactions accountable for the generation of crystal packing. Furthermore, the title compound was screened for antibacterial activities against five pathogenic strains namely: Escherichia coli ATCC 8739, Salmonella typhimurium ATCC 14028, Staphylococus aureus ATCC 6538, Enterococcus feacium ATCC 19434 and Streptocoque B (Sreptococcus agalactiae) and antifungal activities against a clinical strain called Candida albicans ATCC 10231 , corroborating significant activity. In silico investigation of bioactivity of $2 \mathrm{phCr}$ was performed via molecular docking analysis with four types of secreted aspartic proteinases (SAP, SAP1, SAP3, and SAP5) from Candida albicans to explore the antifungal properties in comparison to behavior of known antifungals used to treat Candida albicans, and with three types of $\beta$-ketoacyl acyl carrier protein synthase enzymes (KAS I (FabB), KAS II (FabF) and KAS III $(\mathrm{FabH})$ ) from Escherichia coli in comparison with that of aminothiazole, thilactomycin, and cerulerin antimicrobials. In addition, the complete assignments for $2 \mathrm{phCr}$ are reported considering monodentate coordination for the chromate group.
\end{abstract}

Keywords: Organic-inorganic hybrid material; Chromate(VI); Single crystal X-ray; IR Spectroscopy; Antibacterial and anti-fungal activities; Molecular docking. 


\section{Introduction}

The design and synthesis of new solid materials with controlled structure are a recent defy in solid state chemistry. Up to date a great number of chromates of organic bases have been prepared and used as reagents in mild selective oxidation processes of organic substrates $[1,2]$, so as to display some interesting crystal structure and some special properties in numerous areas, such as nonlinear optical (NLO), catalysis and biology [3,4]. Knowledge of the crystal structures and mechanisms of these associations in hybrid organic-inorganic materials can help to recognize their physic-chemical properties.

A serious medical problem in treatment of infectious organism is the drug resistance. To overcome this issue, a promising method is seemed to be the inhibition of fatty acid synthases because it is essential to cell viability and its specificity for bacteria type. Fatty acid synthases that exist in plants and bacteria is called Type II system. Three types of $\beta$-ketoacyl acyl carrier protein synthase enzymes (KAS I (FabB), KAS II (FabF) and KAS III (FabH) are known to be the most important regulator of the initiation and elongation steps in the pathway [5]. Therefore, the inhibition of these enzymes is highly critical in regulation of fatty acid synthases in bacteria. Chromium based compounds have their own importance in antibacterial activity as suggested by the Ramesh et. al. [6]. Bis(2-phenylethylammonium) chromate(VI) $(2 \mathrm{phCr})$ can be a promising compound to play a role in inhibition of these enzyme, thus we have compared the docking behaviors of $2 \mathrm{phCr}$ to that of aminothiazole, thilactomycin, and cerulerin antimicrobials.

Main purpose of antifungals is to inhibit the related enzymes in target fungi. Antifungals to treat C.albicans have been investigated and classified by Moudgal and Sobel [7] as polyenes, antimetabolites, azoles, and echinocandins. The first three groups of medicines are available for clinical use; therefore we choose ten inhibitors from these groups and their docking behaviors have been compared to that of $2 \mathrm{phCr}$. The target for the potent inhibitors were chosen as the secreted aspartic proteases (SAPs) from $C$. albicans because Saps are among the most important virulence factors of $C$. albicans $[8,9]$.

On the other hand, 2-phenylethylamine is a neuromodulator of catecholamine neurotransmission in the central nervous system [10]. Also, 2-phenylethylamine catabolism by Escherichia coli K12 [11]. In the present contribution, we report the synthesis and their characterization by using X-ray diffraction, infrared spectroscopy and UV-visible Spectroscopy of a novel organic chromate, $\left[\mathrm{C}_{8} \mathrm{H}_{12} \mathrm{~N}\right]_{2} \mathrm{CrO}_{4}$. 


\section{Experimental details}

\subsection{Materials and Physical Measurements}

Infrared (IR) spectrum was recorded at room temperature on a Nicolet IR200 FTIR spectrophotometer in the $4000-400 \mathrm{~cm}^{-1}$ region. UV-Vis spectra were recorded on a Perkin Elmer Lambda 19 spectrophotometer in the $200-800 \mathrm{~nm}$ range. The TG-DTA experiments were carried out with $4.85 \mathrm{mg}$. The sample was placed in an open platinum crucible and heated, from room temperature to $900{ }^{\circ} \mathrm{C}$ an empty crucible was used as reference. Thermal analysis was performed using a multimodule 92 Setaram analyzer.

\subsection{Synthesis}

$\mathrm{CrO}_{3}(1 \mathrm{mmol})$ and 2-phenylethylamine $(2 \mathrm{mmol})$ were dissolved in distilled water $(20 \mathrm{~mL})$. The resulting solution was stirred for 1 hour and then evaporated slowly at room temperature. Yellow sticks of the title compound were obtained from the solution after one week. Elemental analysis, calc. (found): C, 53.28\%(53.32); H, 6.66\%(6.68); N, $7.77 \%(7.75)$; $\mathrm{Cr}$, $14.43 \%(14.33)$.

\subsection{X-ray Structure Determination}

X-ray intensity data were collected on an APEXII, Bruker-AXS diffractometer with MoKa monochromatic radiation $(\lambda=0.71073 \AA)$. The structure was solved by direct methods with SIR97 program [12]. Absorption corrections were performed using the multi-scan technique using the SADABS program [13]. The molecular model was refined by full-matrix leastsquares procedure on $\mathrm{F}^{2}$ with SHELXL-97 [14], included in WINGX package [15], assuming anisotropic displacement parameters for non-hydrogen atoms. The hydrogen atoms bonded to nitrogen atoms were located from a difference map. The rest were determined geometrically and refined using the "riding model" with $\mathrm{C}-\mathrm{H}=0.93 \AA$ for aromatic ring, $0.97 \AA$ for $\mathrm{CH}_{2}$ group, and $\left.\mathrm{U}_{\mathrm{iso}}(\mathrm{H})=1.2 \mathrm{U}_{\mathrm{eq}}(\mathrm{C})\right]$. A summary of the crystallographic data and the structure refinements are given in Table 1.

\section{Quantum chemistry calculations}

The electronic structure and optimized geometry of 2-phenylethylamine chromate and all quantum-chemical calculations were computed by the hybrid B3LYP/6-311++G (d,p) method with the Gaussian 09 software package [16] and the GaussView molecular visualization program [17]. The vibrational wavenumbers, the geometry optimizations, HOMO-LUMO energies and atomic charge distribution were calculated by using DFT method. The wave function obtained from the optimization was used to calculate the topological parameters at 
the BCPs using the Bader's theory of 'Atoms in Molecules, implemented in AIM 2000 software [18]. The Reduced density gradient of the title molecule are graphed by Multiwfn [19] and plotted by VMD program [20]. In addition, the statistical thermodynamic functions (the heat capacity, entropy, and enthalpy) were obtained from the frequency calculations by repeating at different temperatures.

Protein structures of secreted aspartic proteinases SAP (pdb:1ZAP) [8], SAP1 (pdb:2QZW) [21], SAP3 (pdb: 2H6S) [22], and SAP5 (pdb:2QZX) [21] and of $\beta$-ketoacyl acyl carrier protein synthase enzymesFabB (pdb:2VB9) [23], FabF(pdb:4LS5) [24], and FabH(pdb:3iL9) [25] were obtained from the Research Collaboratory for Structural Bioinformatics (RCSB) Protein Data Bank. The structures are cleared from water molecules and preexisting ligands. The hydrogens and Kollman partial charges corresponding electrostatic potential using quantum mechanics are added in AutoDockTools [26] to assign appropriate ionization states for the amino acid residues. Docking calculations and post screening analysis of ligandenzyme interactions are performed using iGEMDOCK [27] on the basis of GEMDOCK (Generic Evolutionary Method for DOCKing Molecules) scoring function [28]. Molecular docking studies were carried out in iGEMDOCK with the accurate docking settings suggested by the program with the following setting; population size is 800 , number of generations is 80 , and number of solutions is 10 . During the calculations, the ligand intramolecular energies are excluded from total energy calculation. The visual representations of ligands in docked state are obtained via PyMol (Schrödinger, LLC, Cambridge, MA, USA) [29] interface.

\section{Antibacterial activity determination}

The antibacterial activity of this compound was evaluated against gram-negative (Escherichia coli ATCC 8739 G(-), Salmonella typhimurium ATCC 14028 G(-)) and gram-positive (Staphylococusaureus ATCC 6538 G(+), Enterococcus feacium ATCC 19434G(+), Streptocoque B (Streptococcus agalactiae) $G(+)$ ) pathogenic bacteria at different concentrations of $100,150,200$ and $250 \mu \mathrm{g} / \mathrm{mL}$ by the modified agar diffusion method [3032]. A suspension of the tested microorganisms was spread on the appropriate solid media plates and incubated overnight at $37^{\circ} \mathrm{C}$. After 1 day, 4-5 loops of pure colonies were transferred to saline solution in a test tube for each bacterial strain and adjusted to the 0.5 McFarland turbidity standards $\left(\sim 10^{8}\right.$ cells $\left./ \mathrm{mL}\right)$. Sterile cotton dipped into the bacterial suspension and the agar plates were streaked three times, each time turning the plate at a $60^{\circ}$ angle and finally rubbing the swab through the edge of the plate. Sterile paper discs (Glass Microfibre filters, Whatman; $6 \mathrm{~mm}$ in diameter) were placed onto inoculated plates and 
impregnated with the diluted solutions in sterile water. The discs were carefully transferred onto the seeded agar plates. Filter paper disc treated with DMSO served as control and Ampicilline $(10 \mathrm{mg} / \mathrm{mL})$ was used as a standard drug. After $24 \mathrm{~h}$ of incubation, the results were recorded by measuring the zones of growth inhibition surrounding the disc. Clear inhibition zones around the discs indicated the presence of antimicrobial activity. All determinations were made in duplicate for each of the compound.

The antifungal activity of this compound and the reacting agents were tested againstthe fungi, Candida albicans ATCC 10231 at three concentrations of 100, 150, 200 and $250 \mu \mathrm{g} / \mathrm{mL}$.Nystatin was used as standard fungicide and DMSO served as a resource of control. The antifungal activities were estimated based on the size of inhibition zone in the discs [33].

\section{Results and discussion}

\subsection{Structure description}

The asymmetric unit of the crystal structure of $\left(\mathrm{C}_{8} \mathrm{H}_{12} \mathrm{~N}\right)_{2} \mathrm{CrO}_{4}$, depicted in an ORTEP drawing Fig.1, consists of two crystallographically independent monoprotonated 2phenylethylammonium cations and one chromate dianion. The structure of this compound can be described as a two-dimensional arrangement of inorganic and organic entities parallel to the plane $(b, c)$ at $x=1 / 4$ and 3/4. Chromate anions and 2-phenylethylammonium cations are linked together by $\mathrm{N}-\mathrm{H} . . . \mathrm{O}$ and weaks $\mathrm{C}-\mathrm{H} \cdots \mathrm{O}$ hydrogen bonds (Fig.2). Interatomic bond lengths and angles of the nitrate anions spread respectively within the ranges 1.6196(13) $1.6774(13) \AA$ and $107.55(6)-112.38(6)^{\circ}$. The distance $\mathrm{Cr}-\mathrm{O} 1$ is notably the shortest (1.6196 (13) A) because O1 is applied in weak hydrogen bonds (Table S1) at the same time as $\mathrm{Cr}-\mathrm{O} 4$ distance is the longest (1.6774 (13) $\AA$ ) because O4 is applied in three hydrogen bonds. These geometrical features have also been noticed in other related crystal structures [34].

For each phenylethylammonium group there are six coplanar atoms forming the mean planes $\mathrm{C} 3 \mathrm{C} 4 \mathrm{C} 5 \mathrm{C} 6 \mathrm{C} 7 \mathrm{C} 8$ and $\mathrm{C} 11 \mathrm{C} 12 \mathrm{C} 13 \mathrm{C} 14 \mathrm{C} 15 \mathrm{C} 16$ their deviation from the mean plans is $\pm 0,0023 \AA$, with a dihedral angle between the two planes of $71,27^{\circ}$. Examination of the 2 phenylethylammonium cation shows that the bond distances and angles show no significant difference from those obtained in other simple salts involving the same organic groups namely, 2-phenylethylammonium p-hydroxybenzoate [35], bis(2-phenylethylammonium) hexachloridostannate(IV) [36] and Bis(2-phenylethylammonium) tetrachloridocobaltate(II) [37]. The $\mathrm{C}-\mathrm{N}$ bond lengths are 1.472(3) and 1.476(3) $\AA$, while the $\mathrm{C}-\mathrm{C}$ bond lengths vary 
from $1.370(3)$ to $1.520(3) \AA$. The N-C-C and C-C-C angles spread in the range 109.93(15) to $121.58(18)^{\circ}$. In the crystal packing of this compound, extensive hydrogen bonding interactions are observed as listed in table 2. The established weak H-bonds [38,39] of types $\mathrm{N}-\mathrm{H} \ldots \mathrm{O}$ and $\mathrm{C}-\mathrm{H}$... $\mathrm{O}$ involve oxygen atoms of the chromate anions as acceptors, and the protonated nitrogen atoms and carbon atoms of 2-phenylethylammonium as donors.

\subsection{Geometrical parameters}

The optimization of the molecular structure was carried out using the Gaussian program, calculated by B3LYP/6-311++G(d,p) level. The geometric parameters of the crystal structure are used to optimize the compound; the optimized geometry is shown in Fig. S1. Table 3 gives a comparison between the optimized geometric parameters and the experimental X-ray crystallographic parameters. From this table, the linkage lengths of the methyl groups bound to $\mathrm{N}$ are, $\mathrm{N} 6-\mathrm{C} 14=1.478$ and $\mathrm{N} 10-\mathrm{C} 31=1.474$, are very close to the normal $\mathrm{C}-\mathrm{N}$ bond length of about 1.48 [40]. The aromatic ring of the crystal structure is somewhat irregular; the variation in the $\mathrm{C}-\mathrm{C}$ bond length is from 1.394 to 1.400 which is compatible with other aromatic rings [41]. As regards the anionic group, we have observed that the optimized bond lengths are slightly different at experimental bond lengths, because theoretical calculations refer to molecules isolated in the gas phase, but the experimental results represent molecules at solid state. Finally, it can be noted the despite the differences between the experimental parameters and the optimal parameters, the latter represent a good approximation.

\subsection{Hirshfeld Surface Analysis}

Intermolecular interactions in the crystal state can be investigated by the use of Hirshfeld surface analysis [42] and their associated finger print plots [43] which are a visual manner for the study of the different types of interactions present within a crystal structure. From the view of the Hirshfeld surface mapped over $d_{\text {norm }}$, Fig. 3 , the red regions on the $d_{\text {norm }}$ surface illustrate the significant $\mathrm{N}-\mathrm{H}$... O and C-H...O hydrogen bonding between ammonium group and chromate anion. The above analysis Fig. 4 can be done by quantitative calculation of 2D fingerprint polts through the Crystal Explorer program [44]. The H...H interactions appear as the largest region of the fingerprint plot with a high concentration in the middle region, shown in light blue, at $\mathrm{d}_{\mathrm{e}}=\mathrm{d}_{\mathrm{i}} \sim 1.2 \AA$ Fig. 4.a with overall Hirshfeld surfaces of $48.8 \%$. The contribution from the $\mathrm{O} \ldots \mathrm{H} / \mathrm{H} \ldots \mathrm{O}$ contacts, corresponding to $\mathrm{N}-\mathrm{H} \ldots \mathrm{O}$ and $\mathrm{C}-\mathrm{H} \ldots \mathrm{O}$ interactions, is represented by a pair of sharp spikes characteristic of a strong hydrogen-bond interaction having almost the same $d_{e}+d_{i} \sim 1.65 \AA$ (Fig. 4.b). 
The distinct pair of wings corresponding to C...H/H...C contacts, Fig. 4.c, at $\mathrm{d}_{\mathrm{e}}+\mathrm{d}_{\mathrm{i}} \sim 2.8 \AA$ due to short interatomic C...H/H...C contacts although $\mathrm{C}-\mathrm{H} \ldots \pi$ interactions are not evident in the structure within the sum of their van der Waals radii. The $1 \%$ contribution from O...O contacts to the Hirshfeld surface.

The enrichment ratio (ER), based on Hirshfeld surface analysis, gives further description of intermolecular interactions operating in a crystal [45]. The ER values are summarized in Table S2. The ER value close to but slightly less than unity, 0.90 , for H...H contacts is in accord with Jelsch expectation [45]. The ER value of 1.28 corresponding to O...H/H...O contacts clearly provides evidence for the formation of $\mathrm{N}-\mathrm{H} \ldots \mathrm{O}$ and $\mathrm{C}-\mathrm{H}$... O interactions. The ER relates to the contacts of O...O and C...H/H...C are of low meaning as they are derived from less important interactions with small contributions in the all parts Hirshfeld surface.

\subsection{Vibrational spectral analysis}

This analysis was performed taking into account monodentate coordinations between the $\left[\mathrm{C}_{8} \mathrm{H}_{12} \mathrm{~N}\right]_{2}$ and $\mathrm{CrO}_{4}$ groups and where each $\mathrm{NH}_{3}{ }^{+}$group has $C_{3 v}$ symmetry while the $\mathrm{CrO}_{4}{ }^{2-}$ group present a tetrahedral environmental with $C_{2 v}$ symmetry. Hence, a total of 135 vibration normal modes are expected for this compound. The scaled quantum mechanical force field (SQMFF) methodology was used [46] together with the Molvib program [47]. The internal normal coordinates used were those reported for compounds with similar groups [48-50] while the scale factors used were those reported by Rauhut, P. Pulay [46]. Here, only those potential energy distribution (PED) contributions $\geq 10 \%$ were considered to perform the complete vibrational assignments. The experimental FT-IR spectrum and the calculated spectrum by the B3LYP/6-311 ++ G (d, p) method in the 4000-400 $\mathrm{cm}^{-1}$ range are shown in Fig. S2, and their assignments using the PED are given in the table S3. This table shows that there is a slight difference between the experimental values and the calculated frequencies, these small differences are due, in the experimental process we recorded spectra is the solid phase sample where the crystalline packing were not considered while the DFT calculations were carried out with an isolated molecule and in the gas phase. Note that the two very strong observed in the experimental IR spectrum at 2685 and $2637 \mathrm{~cm}^{-1}$, predicted by the calculations at 2797 and $2729 \mathrm{~cm}^{-1}$, respectively can be easily assigned to the O5---H13 and O4---H7 stretching modes belonging to the monodentate coordination between the $\mathrm{NH}_{3}{ }^{+}$and $\mathrm{CrO}_{4}{ }^{2-}$ groups. On the other hand, the predicted Raman spectrum expressed in activities is presented in Fig. S3 and compared with the corresponding one converted to Raman intensities by using standard equations [51,52]. We can observe the decrease and increase in the bands 
intensities located in the 4000-2000 and 2000-0 $\mathrm{cm}^{-1}$ regions, respectively when the spectrum is expressed in intensities. Brief discussions on the assignments for some important groups are presented below.

$\mathrm{NH}_{3}{ }^{+}$groups. The $\mathrm{NH}_{3}{ }^{+}$groups have $C_{3 v}$ symmetries and, for this reason, three $\mathrm{N}-\mathrm{H}$ stretching modes are expected for each group where two of them are antisymmetric modes and the other one is a symmetric mode and, where specifically the N6---H7 and N10---H13 bonds have monodentate coordinated with the cromate group. Hence, these modes are predicted in the same region observed for these groups in p-xylylenediaminium bis(nitrate) [48]. Therefore, the band and shoulder at 3166 and $3125 \mathrm{~cm}^{-1}$, respectively are assigned to the antisymmetric and symmetric modes. Note that the other antisymmetric modes of each group are predicted by the SQM calculations coupled with other modes in the lower wavenumber region because these are coordinated bonds but, they are predicted with higher PED contribution at 207 and $162 \mathrm{~cm}^{-1}$ and, for these reasons, they could be easily assigned in these regions. The corresponding deformation modes of these groups are predicted at 1587, 1583, 424 and $404 \mathrm{~cm}^{-1}$, as indicated in Table S3. Hence, the shoulders at 1587 and $419 \mathrm{~cm}^{-1}$ are clearly associated to these vibration modes. One of the two rocking modes expected for these groups are predicted between 1240 and $1052 \mathrm{~cm}^{-1}$ mixed with the rocking modes corresponding to the $\mathrm{CH}_{2}$ groups while the remain modes belong to the coordinate bonds of both groups are predicted with higher PED contributions at 126 and $41 \mathrm{~cm}^{-1}$. Thus, these modes could not be assigned because there are not observed IR bands in this region. The expected twisting modes are predicted by SQM calculations with higher PED contributions at 80 and $24 \mathrm{~cm}^{-1}$ for which they can be assigned in these regions.

$\mathrm{CrO}_{4}{ }^{2-}$ groups. The vibration modes corresponding to this group were assigned taking into account a monodentate coordination which implies that its structure present a tetrahedral environmental with $C_{2 v}$ symmetry. Hence, there are expected two $\mathrm{Cr}=\mathrm{O}$ and $\mathrm{Cr}-\mathrm{O}$ antisymmetric and symmetric stretching modes in the complex. Obviously, the two $\mathrm{Cr}=\mathrm{O}$ stretching modes are predicted by the SQM calculations at higher wavenumbers than the other ones, therefore, the double bonds are predicted at 1028 and $999 \mathrm{~cm}^{-1}$, as in chromyl compounds [53,54] while the other ones are predicted at 774 and $746 \mathrm{~cm}^{-1}$. The $\mathrm{O}=\mathrm{Cr}=\mathrm{O}$ and O-Cr-O deformation modes are predicted at 392 and $283 \mathrm{~cm}^{-1}$ and, for this reason, these modes could not be assigned in this work. The wagging, rocking and twisting modes expected for the $\mathrm{CrO}_{4}{ }^{2-}$ group are predicted in the lower wavenumbers region, these are between 346 and $302 \mathrm{~cm}^{-1}$ and, hence, these modes can be assigned in this region, as indicate in Table 2 . 
$\mathrm{CH}_{2}$ modes. In the complex, there are four $\mathrm{CH}_{2}$ groups, for which bands associated to the four antisymmetric and symmetric stretching modes are expected in the IR spectrum. Hence, the calculations predicted these vibration modes between 2964 and $2877 \mathrm{~cm}^{-1}$, as in pxylylenediaminium bis(nitrate) [48], as can be seen in Table S3. The corresponding deformation, wagging, rocking and twisting modes are predicted in the regions 1437/1421, $1396 / 1299,1346 / 1281$ and $893 / 691 \mathrm{~cm}^{-1}$, and, for these reason, they were assigned in accordance to the calculations and, as assigned for p-xylylenediaminium bis(nitrate) [48].

\section{C-C vibrations}

The $\mathrm{C}=\mathrm{C}$ stretching vibration of the aromatic nucleus and the $\mathrm{C}-\mathrm{C}$ vibration generally are assigned in the regions between $1600-1400 \mathrm{~cm}^{-1}$ and $1200-1070 \mathrm{~cm}^{-1}$ respectively [55]. The phenyl ring $\mathrm{C}=\mathrm{C}$ vibrations stretching can be assigned to the observed bands and shoulders at 1613,1587 and $1541 \mathrm{~cm}^{-1}$ in the FT-IR spectrum because these modes are predicted in the 1591-1569 $\mathrm{cm}^{-1}$ region. The bands for $\mathrm{C}-\mathrm{C}$ stretching vibrations are associated with the observed bands and shoulders at 1283, 1179, 1097, 1012, 986, 901 and $792 \mathrm{~cm}^{-1}$. The vibration frequencies corresponding to the $\mathrm{C}-\mathrm{C}$ stretching modes in the calculated spectrum are predicted at 1294, 1189, 1187, 1070, 1020, 995, 902 and $808 \mathrm{~cm}^{-1}$ while in the terakis(2,6dimethylpiperazine-1,4-diium) tetrakis(sulfate) dihydrate[56] these modes are occur experimentally to a weak bands at 1135 and $1065 \mathrm{~cm}^{-1}$ and predicted at 1089 and $1065 \mathrm{~cm}^{-1}$.

\section{- C-H vibrations}

The vibrational study show that the aromatic $\mathrm{C}-\mathrm{H}$ stretching vibrations are predicted in the 3057-3022 $\mathrm{cm}^{-1}$ wavenumbers region [57] and, for this reason, these modes can be assigned to the FT-IR bands between 3080 and $3022 \mathrm{~cm}^{-1}$. On the other hand, the aromatic $\mathrm{C}-\mathrm{H}$ inplane deformation modes are predicted in the region $1300-1148 \mathrm{~cm}^{-1}$ while the corresponding out-of-plane deformation modes are predicted in the region $991-748 \mathrm{~cm}^{-1}$. These modes are assigned to bands observed in the regions predicted by SQM calculations.

\section{- $\mathbf{C}-\mathbf{N}$ vibrations}

In this complex, the two C-N stretching modes are expected at 1043 and $1028 \mathrm{~cm}^{-1}$ while in the p-xylylenediaminium bis(nitrate) [48] these modes are assigned to the bands at 1005 and $990 \mathrm{~cm}^{-1}$. The shifting of the stretching and bending vibrations of the $\mathrm{NH}_{3}$ group from the free state value confirms the formation of hydrogen bonds of varying strengths in the crystal.

\subsection{UV absorption of $\left(\mathrm{C}_{8} \mathrm{H}_{12} \mathrm{~N}\right)_{2} \mathrm{CrO}_{4}$}


The optical transmittance spectra of this compound samples was recorded in the range of 200-800 nm. The recorded spectra of the grown crystals are shown in Fig. 5.a. The UVVisible spectrum reveals three bands at $292 \mathrm{~nm}, 351 \mathrm{~nm}$ and $439 \mathrm{~nm}$, the first frequency one being the most intense. This behavior is typical for dichromate [58]. The first and second bands correspond respectively to the $\mathrm{n} \rightarrow \sigma^{*}$ and $\mathrm{n} \rightarrow \pi^{*}$ transitions of the chromate $\mathrm{CrO}_{4}{ }^{2-}$ anion. In addition, the third band corresponds to the chromium yellow color. The electronic spectrum of the compound provided by using the Tauc model [59], so this latter was estimated by plotting $(\alpha h v)^{2}$ vs. hv as shown in the inset of Fig. 5.b. and extrapolating the linear portion near the onset of absorption edge to the energy axis. The optical band gaps of $2.98 \mathrm{eV}$, suggesting that the material is a wide-band-gap of dielectric material.

\subsection{UV-Visible spectroscopy}

To highlight electronic transitions, electronic excitation energies and oscillating resistance, we have characterized our compound by UV-Visible spectrophotometry. The UV-visible spectrum of the compound was studied by TD-DFT using the B3LYP method. The experimental and theoretical electronic spectra of compound in DMSO are shown in Fig. S4. The experimental UV-Visible spectrum reveals three bands at $292 \mathrm{~nm}, 351 \mathrm{~nm}$ and $439 \mathrm{~nm}$, the first frequency one being the most intense. This behavior is typical for chromate [58]. The first and second bands correspond respectively to the $n \rightarrow \sigma *$ and $n \rightarrow \pi^{*}$ transitions of the chromate $\mathrm{CrO}_{4}{ }^{2-}$ anion. In addition, the third band and the less intense band centered at 439 corresponds to d-d transition. These bands are observed in the calculated electronic spectra spectrum at $310 \mathrm{~nm}, 348 \mathrm{~nm}$ and $409 \mathrm{~nm}$, the most intense band arising due to electronic transition from HOMO-6 $\rightarrow$ LUMO+1 (64\%) molecular orbitals, the absorption band at 348 $\mathrm{nm}$ arising due to electronic transition from HOMO-5 $\rightarrow$ LUMO (32\%) molecular orbitals, while the absorption band at $409 \mathrm{~nm}$ arising due to electronic transition from HOMO $\rightarrow$ LUMO+1 (90\%) molecular orbitals. The absorption band at $262 \mathrm{~nm}$ is not observed in experimental spectrum of compound in same solvent.

The TD-DFT calculation shows that the maximum value of the oscillator strength is reached for the wavelength $310 \mathrm{~nm}(f=0.0415 \mathrm{a} . \mathrm{u})$ and the low value of the oscillator strength correspond to the first band calculated at $262 \mathrm{~nm}(f=0.0053 \mathrm{a} . \mathrm{u})$. The calculated electronic transitions of high oscillatory strength, along with electronic excitation energies in solvent DMSO are presented in Table 4.

\subsection{Frontier molecular orbitals}


To explain several types of reactions such as their chemical behavior and the stability of the molecular system, we used the study of Frontier molecular orbital. The pictorial representation of the HOMO and the LUMO of our compound is given in Fig. 6. This figure shows that the highest occupied molecular orbital HOMO that could act as electron donor is delocalized over the organic cation, the lowest unoccupied molecular orbital LUMO that could act as electron acceptor is delocalized over the anionic group [59].

The energy values of the HOMO-LUMO molecular orbitals are summarized in Table S4, this table shows that these energies are all negative, so can be concluded the crystal structure is stable [60]. Likewise the space of energy, calculates $-3.3982 \mathrm{eV}$ is relatively high, is an index of high stability and reflects the chemical stability of the molecule. By using the calculated energy values, can be determined the global chemical reactivity descriptors of the molecule [61], which are Ionization potential (I), Electron affinity (A), Electrophilicity ( $\omega)$, Chemical potential $(\mu)$, Electronegativity $(\chi)$, Hardness ( $\eta$, and Softness (S).

$\mathrm{I}=-\mathrm{E}_{\mathrm{HOMO}}, \mathrm{A}=-\mathrm{E}_{\mathrm{LUMO}}, \quad \mu=\frac{-(i+A)}{2}, \quad \eta=\frac{i-A}{2} \chi=\frac{i+A}{2} \quad \mathrm{~S}=\frac{1}{n}$

Parr et al. [62] have defined the global electrophilicity $(\omega) \omega=\frac{\mu^{2}}{2 \eta}$. The quantum chemical parameters of the molecule are summarized in Table S5.

\subsection{Thermal behavior}

The two curves corresponding to differential and thermogravimetric analysis (DTA/TG) under argon flow are given in the Fig. 7. The DTA curve shows that the title compound is stable until $100^{\circ} \mathrm{C}$, where it undergoes a melting transformation at $133{ }^{\circ} \mathrm{C}$, indeed, this phenomenon is further confirmed by the heating of this compound on a Kofler bench which makes it possible to estimate their melting temperature. This temperature is very close to that observed on the DTA curve. At the same time, the material begins to undergo a continuous decomposition in a wide temperature range [100-900 ${ }^{\circ} \mathrm{C}$ ], from which an important weight loss is observed on the TG. A black residue is obtained revealing the presence of residual organic species mixed with chromium.

\subsection{AIM calculation: Topological parameters at bond critical points (BCP)}

The AIM approach consists of defining the various properties of any chemical bond including hydrogen bonds. For this purpose the critical point (BCP) is used for the identification of the chemical bonds between the atoms and the interatomic interaction. Geometrical and topological parameters are a useful tool to characterize the strength and nature of the H-bond. 
But these criteria for the existence of hydrogen bond are frequently considered as insufficient, so one must be based on Koch and Popelier [63] criteria to confirm the existence of hydrogen bond. These criteria are (i) the existence of bond critical point for the proton (H)-acceptor (A) contact as a confirmation of the existence of hydrogen bonding interaction, (ii) the value of electron density $\rho(\mathrm{H} \ldots \mathrm{A})$ should be within the range of $0.002-0.040$ a.u, (iii) The corresponding Laplacian $\nabla^{2} \rho_{\mathrm{BCP}}$ should be within the range of $0.024-0.139$ a.u. according to Rozas et al. [64], the interactions may be classified as follows:

(i) Strong H-bonds are characterized by $\nabla^{2} \rho_{(\mathrm{BCP})}<0 ; \mathrm{H}_{(\mathrm{BCP})}<0 ; \mathrm{E}_{\mathrm{HB}}>24.0 \mathrm{kcal} / \mathrm{mol}$ and their covalent character is established (ii) medium H-bonds are characterized by $\nabla^{2} \rho_{(\mathrm{BCP})}>0$; $\mathrm{H}_{(\mathrm{BCP})}<0 ; 12.0<\mathrm{E}_{\mathrm{HB}}<24.0 \mathrm{kcal} / \mathrm{mol}$ and their partially covalent character is established (iii) weak H-bonds are characterized $\nabla^{2} \rho_{(\mathrm{BCP})}>0 ; \mathrm{H}(\mathrm{BCP})>0$; EHB $<12.0 \mathrm{kcal} / \mathrm{mol}$ and they are mainly electrostatic and the distance between interacting atoms is greater than the sum of van der Waal's radii of these atoms.

Molecular graph of crystalline structure using AIM program at B3LYP/6-311G(d,p) level is shown in Fig. 8. Geometrical and topological parameters for bonds of interacting atoms in phenylethylammonium chromate crystal are given in Table 5. On the basis of these parameters of this table $\mathrm{O} 46 \ldots \mathrm{H} 2, \mathrm{O} 46 \ldots \mathrm{H} 31, \mathrm{O} 46 \ldots \mathrm{H} 23, \mathrm{H} 31 \ldots \mathrm{H} 5, \mathrm{H} 31 \ldots \mathrm{H} 8, \mathrm{H} 11 \ldots \mathrm{C} 32$, H11...C41 are weak hydrogen bonds. The various type of interactions visualized in molecular graph are classified on the basis of geometrical, topological and energetic parameters. In this article, the Bader's theory application is used to estimate hydrogen bond energy (E). Espinosa [65] proposed proportionality between hydrogen bond energy (E) and potential energy density $\left(\mathrm{V}_{\mathrm{BCP}}\right)$ at $\mathrm{H}$... O contact: $\mathrm{E}=\frac{1}{2}\left(\mathrm{~V}_{\mathrm{BCP}}\right)$. According to this equation the energy of these hydrogen bonds between -2.0123 and $-37.5714(\mathrm{~kJ} / \mathrm{mol})$. In order to investigate the effect of $\pi$-electron delocalization in bonds associated with $\mathrm{N}$ and $\mathrm{O}$ atoms of $\mathrm{N}-\mathrm{H} \cdot \cdots \mathrm{O}$, the analysis of the bond ellipticity is performed. The ellipticities $(\boldsymbol{\varepsilon})$ of bond of aromatic ring at BCP are in range of 0.0281-5.1480. The $\varepsilon$ values confirm the presence of resonance assisted intermolecular hydrogen bonds.

\subsection{Thermodynamic properties}

Thermodynamics is defined as the science of all phenomena which depends from temperature and its changes. Thermodynamic properties are characteristics used to describe a physical system. On the basis of the vibration analysis at B3LYP / 6-311 ++G (d, p) level Fig. S5, the standard static thermodynamic functions: heat capacity $(\mathrm{Cp})$, entropy $(\mathrm{S})$ and enthalpy change 
$(\mathrm{H})$ for the crystal structure were obtained from the theoretical harmonic frequencies are reported in Table S6. From this table, it can be seen that these thermodynamic functions are increasing with temperature ranging from 100 to $1000 \mathrm{k}$. This is due to the fact that the molecular vibratory intensities increase with increasing temperature [66]. The correlation equations between heat capacities, entropies, enthalpy changes and temperatures were fitted by quadratic formulas, and the corresponding fitting factors $\left(\mathrm{R}^{2}\right)$ for these thermodynamic properties are $0.99916,0.9992$ and 0.99992 , respectively. The equations of adjustment and the figure of thermodynamic properties are as follows:

$$
\begin{aligned}
& \mathrm{C}_{\mathrm{p}, \mathrm{m}}{ }^{\mathrm{o}}=38.75607+1.38804 \mathrm{~T}-5.56858 \times 10^{-4} \mathrm{~T}^{2}\left(\mathrm{R}^{2}=0.99916\right) \\
& \mathrm{S}_{\mathrm{m}}{ }^{\mathrm{o}}=379.97352+1.57392 \mathrm{~T}-3.69488 \times 10^{-4} \mathrm{~T}^{2}\left(\mathrm{R}^{2}=0.99992\right) \\
& \mathrm{H}_{\mathrm{m}}{ }^{\mathrm{o}}=-14.85397+0.17999 \mathrm{~T}+3.90745 \times 10^{-4} \mathrm{~T}^{2}\left(\mathrm{R}^{2}=0.99992\right)
\end{aligned}
$$

From these thermodynamic data we can calculate other thermodynamic energies and also we can estimate the directions of chemical reactions according to the second law of thermodynamics in the thermo-chemical field [67]. These equations above will be helpful for deepened studies of the title compound. We note that all thermodynamic calculations were done in the gas phase and could not be used in solution.

\subsection{Reduced density gradient (RDG) analysis}

To study non-covalent interactions Johnson et al. [68] developed an approach based on the electronic density and its derivatives named RDG. The RDG were defined using the following equation.

$$
\mathrm{RDG}(\mathrm{r})=\frac{1}{2\left(3 \pi^{2}\right)^{1 / 3}} \frac{|\nabla \rho(r)|}{\rho(r)^{4} / 3}
$$

The dispersion diagram, RDG with respect to the electronic density $\rho$ multiplied by the sign of $\lambda_{2}$, shows RDG peaks and these spikes corresponding to the hydrogen bonding interactions, the van der Waals interactions and the steric effect Fig. 9.a. Low density values appear to be an indicator of stronger attractive interactions. The bluer means the stronger interactive interaction; the green can be identified as van der Waals interaction region and the red show a strong steric effect Fig. 9.b. The RDG peak toward -0.22 corresponds a strong interaction between oxygen and hydrogen which also confirmed by the color blue in the color scaling. The area surrounded by a green circle can be identified as van der Waals interaction region and the regions in the center of rings and the others show strong steric effect. These results are comparable to those found in the AIM calculation 


\subsection{Analysis of Molecular Electrostatic Potential Surface (MEP)}

The molecular electrostatic potential (MEP) is related to the electron density, it is very useful to explain the effects of polarization and charge transfer in the molecule. The MEP has been widely used as a molecular descriptor in determination the sites for electrophilic and nucleophilic reactions as well as hydrogen bonding interactions $[69,70]$. The molecular electrostatic potential $\mathrm{V}(\mathrm{r})$, at a given point, is created in space in the vicinity of a molecule by molecular electrons of the nuclei and a positive test charge. The MEP values were defined using the following equation [71].

$$
\mathrm{V}(\mathrm{r})=\Sigma_{A} \frac{z_{A}}{\left(R_{A^{-}} r\right)}-\int \frac{\rho\left(r^{5}\right)}{\left(r^{\prime}-r\right)} \mathrm{dr}^{\prime}
$$

In which $\rho\left(r^{\prime}\right)$ is the electron density function of the molecule, $Z_{A}$ is the charge of nucleus allocated at $R_{A}$ and $r^{\prime}$ is the dummy integration variable. The different values of the electrostatic potential at the surface are represented by different colors, red represents the region of the electronegative electrostatic potential, (electron rich), blue represents the region of the most positive electrostatic potential (electron deficient), yellow represents the region of electrostatic potential slightly electron deficient and green represents the region of the neutral potential. Potential increase in order red $<$ orange $<$ yellow $<$ green $<$ blue [72]. The electrostatic potential correlates with the dipole moment, electronegativity, partial charges and site of chemical reactivity of the molecule. To study the chemical reactivity of the molecule, the electron density and surface area of the electrostatic potential are plotted using B3LYP/6$311++\mathrm{G}(\mathrm{d}, \mathrm{p})$. The total electron density mapped with electrostatic potential surface of crystalline structure is shown in Fig.10. From this figure, it is clear that the region around the anionic group represents the most negative potential region (red, oxygen atoms) are regarded as electrophilic regions due to the strong intermolecular hydrogen bond and the positive potential sites are around the nitrogen atoms nucleophilic regions. The MEP surface provides the necessary information for the most reactive site for both electrophilic and nucleophilic attack.

\section{Biological activity}

\subsection{Antibacterial activity}


The antibacterial activity of phenylethylammonium chromate(VI) was tested against five pathogenic organismsnamed Escherichia coli ATCC 8739, Salmonella typhimurium ATCC 14028, Staphylococusaureus ATCC 6538, Enterococcus feacium ATCC 19434 and Streptocoque B. Fig. S6.a shows bar diagrams of the inhibition zone growth diameter (IZD) under three different concentrations $(100,150,200$ and $250 \mu \mathrm{g} / \mathrm{mL})$. This study reveals that our compound is active against five bacteria with varying but significant degrees of inhibition. This inhibitory power in the process of multiplication of these microbes is probably due to blockages of the active sites of these microbes. This biological activity in this compound can be acquired by means of the hydrogen bonds network.

Evaluation of anti-Candida activities of the compound was carried out on a clinical strain called Candida albicans ATCC 10231(Fig. S6.b).The results of these tests show clearly an annihilation of the yeast growth process which is much more promising in the compound synthesized with zones of inhibition ranging from 7 to $11.5 \mathrm{~mm}$. Similarly, we note the antifungal effect is an increasing function of the concentration. Indeed the increase of the concentration improves the antifungal power.

\subsection{In silico evaluation of antifungal characteristics of $2 \mathrm{phCr}$}

Antifungal test of $2 \mathrm{phCr}$ was performed in comparison to ten clinically used antifungals among polyenes, azoles, and antimetabolite groups and binding energies that are calculated as the sum of the H-bond, van der Waals, and electronic interaction energies are summarized in Table 6. Polyenes bind to enzymes most strongly, the flucytosine is the weakest binding inhibitor, and azole group compounds binding energies are at moderate level. Ligand-enzyme interactions for the compounds studied here are mostly H-bond and van der Waals type. Only polyenes rarely show some electronic interactions. $2 \mathrm{phCr}$ is a relatively weakly binding compound with the exception in the case of SAP3. The compound interacts with this enzyme even better than some azole compounds.

Another important characteristic in these analyses is the similarity in interactions that is mostly depends on the binding site where the compounds reside. Localizations of compounds at the binding sites and cluster representation of ligand-enzyme interactions are given in Table 7. Cluster representation is presented as green-black pictorials where the green color marks the interacting residues with each ligand in their docked geometry. Similarity in green mark pattern is directly related to positioning and interactional behaviors of ligands. This figure provides clear evidence on enzyme type dependency of inhibitory behaviors of compounds. The last raw in the table is the $\mathrm{H}$-bond interacting residues and their interaction strengths in 
$\mathrm{kcal} / \mathrm{mol}$ for only $2 \mathrm{phCr}$. In the case of SAP, all compounds reside at the same binding site except flucytosine which resides at the outer surface of the enzyme. According to the cluster representation $2 \mathrm{phCr}$ behaves most likely albaconazole but with $15.1 \mathrm{kcal} / \mathrm{mol}$ weaker binding energy. For the SAP1, the docking sites for ligands vary more than that of SAP.Posaconazole (at middle of protein), and Amphotericin B and Flucytosine at bottom resides at different sites than the rest of the compounds. $2 \mathrm{phCr}$ is localized at where the most of the ligands are docked and shows nearly same interaction profile with itraconazole but has $24.4 \mathrm{kcal} / \mathrm{mol}$ weaker interaction energy. Interactions of the $2 \mathrm{phCr}$ with SAP3 and SAP5 are actually not highly correlated with the other compounds. Although the $2 \mathrm{phCr}$ goes into the same binding site with six other known inhibitors in SAP3, the interaction profile is not desirably similar, but still can be considered under the same tree. Finally, the docking of $2 \mathrm{phCr}$ to SAP5 is totally at different binding site than the other compounds. This indicates that the antifungal effect of our compound depends on the type of SAP enzyme.

\subsection{In silico evaluation of antibacterial characteristics of $2 \mathrm{phCr}$}

In silico antibacterial test for the $2 \mathrm{phCr}$ compound is performed in comparison to the aminothiazole, cerulerin, and thilactomycin antimicrobials of E.coli. $\beta$-ketoacyl acyl carrier protein synthase enzymes from E.coli were chosen to be the target structure because the inhibition of these enzymes is highly critical in regulation of fatty acid synthases in bacteria. Table 8 gives the summary of energetic results of the docking analysis. Excitingly, $2 \mathrm{phCr}$ results in tightest docking in FabF and FabH enzymes, and just below the aminothiazole in FabB. This result implies that 2 phCr can be a strong antibacterial agent for the E.coli if it also shows similar interaction profile with known inhibitors.

Localizations of antibacterial agents and $2 \mathrm{phCr}$ at the binding sites and cluster representation of ligand-enzyme interactions are given in Table S7. For the FabB, amonothiazole and 2phCr reside at the same binding site and results in greatly similar interaction profile. The other compounds are localized at different binding sites. Thus, we can say that $2 \mathrm{phCr}$ can be considered as a compatible inhibitor of FabB as good as aminothiazole. The situation is totally alters for the other two enzymes: all compounds reside at different sites in FabF and the interaction profile of our compound is quite different than that of the other inhibitors, even though the compounds all localize at the same binding site in $\mathrm{FabH}$, interactions of $2 \mathrm{phCr}$ differs significantly.

\section{Conclusion}


In this work, the newly-prepared organic-inorganic $2 \mathrm{phCr}$ compound was found to crystallize at room temperature in the monoclinic system (C2/c space group). The crystal structure can be described by two-dimensional arrangement of inorganic and organic entities parallel to the plane $(b, c)$ at $x=1 / 4$ and $3 / 4$. The crystal packing is stabilized by involved hydrogenbonding such as $\mathrm{N}-\mathrm{H}^{\cdots} \mathrm{O} \mathrm{O}$ and $\mathrm{C}-\mathrm{H}^{\cdots} \mathrm{O}$ bonds among $\left[\mathrm{C}_{8} \mathrm{H}_{12} \mathrm{~N}\right]^{+}$entities and the $\left[\mathrm{CrO}_{4}\right]^{2-}$ anions. The Hirshfeld surface analysis reveals the percentage of intermolecular contacts of the title compound. The compound was characterized by using the FTIR and UV-visible spectroscopies. Their structural and vibrational spectra calculated by DFT/B3LYP method are in good agreement with the experimental results. The (TG/DTA) thermal analysis was performed to establish the thermal stability of the crystal. The later analysis show that the $\left(\mathrm{C}_{8} \mathrm{H}_{12} \mathrm{~N}\right)_{2} \mathrm{CrO}_{4}$ crystal is stable until $100^{\circ} \mathrm{C}$. To study reactivity given that an approaching electrophile will be attracted to negative regions, where the electron distribution effect is dominant, the MEP also given. The UV-Vis spectral analysis of the title molecule was presented both experimentally and theoretically. AIM topological analysis has been presented to study the formation of the intermolecular hydrogen bond and the sign of the second Hessian eigenvalue were used to give the type of interaction, and its strength can be derived from the density on the noncovalent interaction surface. Our study showed that $2 \mathrm{phCr}$ can be considered as a relatively weakly binding potent antifungal for C.albican and the antifungal effect of our compound depends on the type of SAP enzyme. Antibacterial properties of $2 \mathrm{phCr}$ are highly strong but show significant differences from the selected antibacterial compounds studied here. Additionally, the assignments of the 135 vibration normal modes for $2 \mathrm{phCr}$ are reported considering monodentate coordination for the chromate group. 


\section{References}

[1] K. Balasubramanian and V. Prathibe, Ind. J. Chem. 25B (1986) 326.

[2] J. Muzart, Chromium-catalyzed oxidations in organic synthesis, Chem. Rev. 92 (1992) 113-140.

[3] G. Le Flem, Eur . J. Solide State Inorg. Chem, 28 (1991).

[4] C. B. Aakerôy, P. B. Hitchcok, B. D. Molyle and K. R. Seddo, A Novel Class of Salts for Second Harmonic Generation, J. Chem. Soc. Chem. Commun., 23 (1989) 18561859.

[5] G. Sabbagh, N. Berakdar, Docking studies of flavonoid compounds as inhibitors of $\beta$ ketoacyl acyl carrier protein synthase I (Kas I) of Escherichia coli, J. Mol. Graph. Model. 61 (2015) 214-223.

[6] C. Ramesh, K. Mohan, M. Senthil, V. Ragunathan, Antibacterial activity of $\mathrm{Cr}_{2} \mathrm{O}_{3}$ nanoparticles against E.coli; reduction of chromate ions by Arachis hypogaea leaves, Aech. Appl. Sci. Res., 4 (2012) 1894-1900.

[7] V. Moudgal, J. Sobel, Antifungals to treat Candida albicans, Expert Opin. Pharmacother. 11 (2010) 2037-2048.

[8] C. Abad-Zapatero, R. Goldman, S.W. Muchmore, C. Hutchins, K. Stewart, J. Navaza, C.D. Payne, T.L. Ray, Structure of a secreted aspartic protease from $C$. albicans complexed with a potent inhibitor: Implications for the design of antifungal agents, Protein Sci. 5(1996) 640-652.

[9] W. Li, D. Yu, S. Gao, J. Lin, Z. Chen, W. Zhao, Role of Candida albicans-Secreted Aspartyl Proteinases (Saps) in Severe Early Childhood Caries, Int. J. Mol. Sci. 15 (2014) 10766-10779.

[10] I. A. Paterson, A. V. Juorio, A. A. Boulton, 2-Phenylethylamine: A Modulator of Catecholamine Transmission in the Mammalian Central Nervous System?, J. Neurochemistry, 55 (6) (1990) 1827-1837.

[11] S. Parrott, S. Jones and R. A. Cooper, 2-Phenylethylamine Catabolism by Escherichia coli K12, Journal of General Microbiology 133 (1987) 347-351.

[12] A. Altomare, M. C. Burla, M. Camalli, G. L. Cascarano, C. Giacovazzo, A.Guagliardi, A. G. G. Moliterni, G. Polidori, R. Spagna, SIR97: a new tool for crystal structure determination and refinement, J. Appl. Cryst. 32 (1999) 115-119.

[13] Bruker (2006).APEX2, SAINT and SADABS.Bruker AXS Inc., Madison, Wisconsin, USA 
[14] G. M. Sheldrick, Crystal structure refinement with SHELXL, ActaCryst. C71 (2015)38.

[15] L. J. Farrugia, WinGX and ORTEP for Windows: an update, J. Appl. Cryst. 45 (2012) 849-854.

[16] M. J. Frisch, G. W. Trucks, H. B. Schlegel, G. E. Scuseria, J. R. Cheeseman, M. A. Robb, G. Scalmani, V. Barone, B. Mennucci, G. A. Petersson, H. Nakatsuji, M. Caricato, X. Li, H. P. Hratchian, A. F. Izmzylov, J. Bloino, G. Zheng, J. L. Sonnenberg, M. Hada, M. Ehara, K. Toyota, R. Fukuda, J. Ishida, M. Hasegawa, T. Nakajima, Y. Honda, O. Kitao, H. Nakai, T. Vreven, J. A. Montgomery, J. E. Peralta Jr., F. Ogliaro,M. Bearpark, J. J. Heyd, E. Brothers, K. N. Kudin, V. N. Staroverov, R. Kobayashi, J. Normand, A. Raghavachari, A. Rendell, J. C. Burant, S. S. Iyengar, J. Tomasi, M. Cossi, N. Rega, J. M. Millan, M. Klene, J. E. Knox, J. B. Cross, V. Bakken, C. Adamo, J. Jaramillo, R. Gomperts, R. E. Stratmann, O. Yazyev, A. J. Austin, R. Cammi, C. Pomelli, J. W. Ochterski, R. L. Martin, K. Morokuma, V. G. Zakrzewski, G. A. Voth, P. Salvador, J. J.Dannerberg, S. Dapprich, A. D. Daniels, J. Farkas, B. Foresman, J. V. Ortiz, J. Cioslowski and D. J. Fox, GAUSSIAN 09, Revision, Gaussian, Inc., Wallingford CT, 2010

[17] Computer program Gauss View 5.0.9, Gaussian Inc, Wallingford, CT 06492 USA.

[18] R. F. W. Bader, Atoms in Molecules, A Quantum Theory, Oxford University Press, Oxford, 1990.

[19] T. Lu, F. Chen, Multiwfn: A multifunctional wavefunction analyzer, J. Comput. Chem. 33 (2012) 580-592.

[20] W. Humphrey, A. Dalke, K. Schulten, VMD—Visual molecular dynamics, J. Mol. Graph. 14 (1996) 33-38 27-8.

[21] C. Borelli, E. Ruge, J.H. Lee, M. Schaller, A. Vogelsang, M. Monod, H.C. Korting, R. Huber, K. Maskos, X-ray structures of Sap1 and Sap5: Structural comparison of the secreted aspartic proteinases from Candida albicans, Proteins Struct. Funct. Bioinforma. 72 (2008) 1308-1319.

[22] C. Borelli, E. Ruge, M. Schaller, M. Monod, H.C. Korting, R. Huber, K. Maskos, The crystal structure of the secreted aspartic proteinase 3 from Candida albicans and its complex with pepstatin A, Proteins Struct. Funct. Bioinforma. 68 (2007) 738-748.

[23] G. Pappenberger, T. Schulz-Gasch, E. Kusznir, F. Müller, M. Hennig, Structureassisted discovery of an aminothiazole derivative as a lead molecule for inhibition of bacterial fatty-acid synthesis, Acta Cryst. D63 (2007) 1208-1216. 
[24] F. Trajtenberg, S. Altabe, N. Larrieux, F. Ficarra, D. de Mendoza, A. Buschiazzo, G.E. Schujman, Structural insights into bacterial resistance to cerulenin, FEBS J. 281 (2014) 2324-2338.

[25] K. S. Gajiwala, S. Margosiak, J. Lu, J. Cortez, Y. Su, Z. Nie, K. Appelt, Crystal structures of bacterial FabH suggest a molecular basis for the substrate specificity of the enzyme, FEBS Lett. 583 (2009) 2939-2946.

[26] G. Morris, R. Huey, AutoDock4 and AutoDockTools4: Automated docking with selective receptor flexibility, J. Comput. Chem. 30 (2009) 2785-2791.

[27] K.-C. Hsu, Y.-F. Chen, S.-R. Lin, J.-M. Yang, iGEMDOCK: a graphical environment of enhancing GEMDOCK using pharmacological interactions and post-screening analysis, BMC Bioinformatics 12 Suppl 1 (2011) S33.

[28] J.-M. Yang, C.-C. Chen, GEMDOCK: A generic evolutionary method for molecular docking, Proteins Struct. Funct. Bioinforma. 55 (2004) 288-304.

[29] L. The PyMOL Molecular Graphics System, Version 1.8 Schrödinger, (2015).

[30] G. Tadesse, E. Ephraim, and M. Ashenafi, Assessment of the antimicrobial activity of lactic acid bacteria isolated from Borde and Shamita, traditional Ethiopian fermented beverages, on some foodborne pathogens and effect of growth medium on the inhibitory activity, 5 (2005). Int. J. Food Saf., 13-20.

[31] O. Y. Celikatas, E. Bendir, and F. V. Sukan, In vitro antioxidant activities of Rosmarinus officinalis extracts treated with supercritical carbon dioxide, 101 (2007) Food Chem., 1457-1464.

[32] G. Sacchetti, S. Maietti, M. Muzzoli, M. Scaglianti, S. Manfredini, M. Radice, and R. Bruni, Comparative evaluation of 11 essential oils of different origin as functional antioxidants, antiradicals and antimicrobials in foods, 91 (2005) Food Chem., 621632.

[33] S. Gopalakrishnan, N. T. Nevaditha, C. V. Mythili, Antibacterial activity of azo compounds synthesized from the natural renewable source, cardanol, J. Chem. Pharm. Res. 3(4) (2011) 490-497.

[34] S. Trabelsi, M.Essid, T. Roisnel, M. Rzaigui and H. Marouani, Propane-1,2diammonium chromate(VI), Acta Cryst. E70 (2014) m84-m85.

[35] S. Sudhahar, M. Krishna Kumar, P. Pandi, R. Mohan Kumar, 2Phenylethylammonium p-hydroxybenzoate: Growth, structural, spectral, thermal, optical and mechanical characterization, Optik - International Journal for Light and Electron Optics, 125 (2014) 4327-4332. 
[36] D. G. Billing, A. Lemmerer and M. Rademeyer, Bis(1-phenylethylammonium) hexachloridostannate(IV) and bis(2-phenylethylammonium) hexachloridostannate(IV), Acta Cryst. C63 (2007) m101-m104.

[37] I. Oh, D. Kim, Y-D. Huh, Y. Park, J. M. S. Parka and S-H. Parkd, Bis(2-phenylethylammonium) tetrachloridocobaltate(II), Acta Cryst. E67 (2011) m522-m523.

[38] R. H. Blessing, Hydrogen bonding and thermal vibrations in crystalline phosphate salts of histidine and imidazole, ActaCryst. B42 (1986) 613-621.

[39] I. D. Brown, On the geometry of O-H $\cdots O$ hydrogen bonds, ActaCryst. A32 (1976) 2431.

[40] K. B. Benzon, H. T. Varghese, C. Y. Panicker, K. Pradhan, B. K. Tiwary, A. K. Nanda, C. Van Alsenoy, Spectroscopic and theoretical characterization of 2-(4methoxyphenyl)-4,5-dimethyl-1H-imidazole 3-oxide, Spectrochim. Acta 151 (2015) 965-979.

[41] J. B. Bhagyasree, H. T. Varghese, C. Y. Panicker, J. Samuel, C. Van Alsenoy, K. Bolelli, I. Yildiz, E. Aki, Vibrational spectroscopic (FT-IR, FT-Raman, ${ }^{1} \mathrm{H}$ NMR and UV) investigations and computational study of 5-nitro-2-(4-nitrobenzyl) benzoxazole, Spectrochim. Acta 102 (2013) 99-113.

[42] J. J. McKinnon, A. S. Mitchell, M. A. Spackman, Hirshfeld Surfaces: A New Tool for Visualising and Exploring Molecular Crystals, Chem. A Eur. 4 (1998) 2136.

[43] M. A. Spackman, J. J. McKinnon, Fingerprinting intermolecular interactions in molecular crystals, CrystEngComm, 4, (2002), 378.

[44] S. K. Wolff, D. J. Grimwood, J. J. McKinnon, D. Jayatilaka, M. A. Spackamn, “Crystal Explorer 3.1,” University of Westren Australia, Perth, 2013.

[45] C. Jelsch, K. Ejsmont, L. Huder, The enrichment ratio of atomic contacts in crystals, an indicator derived from the Hirshfeld surface analysis, IUCrJ. 1 (2014) 119-128.

[46] a) G. Rauhut, P. Pulay, J. Phys. Chem. 99 (1995) 3093-3099. b) Correction: G. Rauhut, P. Pulay, J. Phys. Chem. 99 (1995) 14572.

[47] T. Sundius, Scaling of ab initio force fields by MOLVIB, Vib. Spectrosc. 29 (2002) 89-95.

[48] S. Gatfaoui, N. Issaoui, S.A. Brandán, T. Roisnel, H. Marouani, Synthesis and Characterization of p-Xylylenediaminium bis(nitrate). Effects of the Coordination Modes of Nitrate Groups on Their Structural and Vibrational properties, J. Mol. Struct. 1151 (2018) 152-168. 
[49] S. Gatfaoui, N. Issaoui, A. Mezni, F. Bardak, T. Roisnel, A. Atac, H. Marouani, Synthesis, structural and spectroscopic features, and investigation of bioactive nature of a novel organic-inorganic hybrid material 1H-1,2,4-triazole-4-ium trioxonitrate, J. Mol. Struct. 1150 (2017) 242-257.

[50] H.A. Höppe, K. Kazmierczak, E. Romano, S.A. Brandán, A structural and vibrational study on the first potassium borosulfate, $\mathrm{K}_{5}\left[\mathrm{~B}\left(\mathrm{SO}_{4}\right)_{4}\right]$ by using the FTIR-Raman and DFT calculations, J. Mol. Struct. 1037 (2013) 294-300.

[51] G. Keresztury, S. Holly, G. Besenyei, J. Varga, A.Y. Wang, J.R. Durig, Vibrational spectra of monothiocarbamates-II. IR and Raman spectra, vibrational assignment, conformational analysis and ab initio calculations of S-methyl-N,N-dimethylthiocarbamate Spectrochim. Acta, 49A (1993) 2007-2026.

[52] D. Michalska, R. Wysokinski, The prediction of Raman spectra of platinum(II) anticancer drugs by density functional theory, Chemical Physics Letters, 403 (2005) 211-217.

[53] S. A. Brandán, Volume 1: A Structural and Vibrational Study of the Chromyl Chlorosulfate, Fluorosulfate, and Nitrate Compounds, Editor by Ken Derham, Springer Science, Business Media B.V., Van Godewijckstraat 30, 3311 GZ Dordrecht, Netherlands. ISBN: 978-94-007-5762-2 (Print) 978-94-007-5763-9 (Online) October 2012.

[54] S. A. Brandán, Volume 2: A Structural and Vibrational Investigation into Chromylazide, Acetate, Perchlorate, and Thiocyanate Compounds, Editor by Ken Derham, Springer Science, Business Media B.V., Van Godewijckstraat 30, 3311 GZ Dordrecht, Netherlands. ISBN: 978-94-007-5753-0 (Print) 978-94-007-5754-7 (Online) October 2012.

[55] S. Sudhahar, M. KrishnaKumar, P.Pandia \& R. Mohan Kumara, Optik 125 (2014) 4327.

[56] C. Ben M'leh, S. A. Brandán, N. Issaoui, T. Roisnel, H. Marouani, Synthesis, molecular structure, vibrational and theoretical studies of a new non-centrosymmetric organic sulphate with promising NLO properties, J. Mol. Struct. 1171 (2018) 771-785.

[57] M. K. Marchewka, Infrared and Raman spectra of melaminium chloride hemihydrate Mater. Sci. Eng. B.95 (2002) 214-221.

[58] B. M. Weckhuysen, A. A. Verberckmoes, A. R. De Baets \& R. A. Schoonheydt, Diffuse Reflectance Spectroscopy of Supported Chromium Oxide Catalysts: A Self-Modeling Mixture Analysis, J. Catal. 166 (1997) 160.

[59] J. Tauc, Optical properties and electronic structure of amorphous Ge and Si, Mater. Res. Bull. 3 (1968) 37-46. 
[60] W. Rui-Feng, Z. Tong-Lai, Q. Xiao-Jing, Z. Jian-Guo, Y. Li, Y. Wei, Synthesis and crystal structure of 7-nitro-5-sulfo-napthalene-1,4-dicarboxylate acid, Chinese J. Struct. Chem. 25 (2006) 849-853.

[61] R.G. Parr, P.K. Chattaraj, Principle of maximum hardness, J. Am. Chem. Soc. 113 (1991) 1854-1855.

[62] R.G. Parr, L.V. Szentpaly, Electrophilicity Index, J. Am. Chem. Soc. 121 (1999) 1922-1924.

[63] U. Koch, P. Popelier, Characterization of C-H-O Hydrogen Bonds on the Basis of the Charge Density, J. Phys. Chem. Soc. A99 (1995) 9747.

[64] I. Rozas, I. Alkorta, J. Elguero, Behavior of Ylides Containing N, O, and C Atoms as Hydrogen Bond Acceptors, J. Am. Chem. Soc. 122 (2000) 11154-11161.

[65] E. Espinosa, E. Molins, C. Lecomte, Hydrogen bond strengths revealed by topological analyses of experimentally observed electron densities, Chem. Phys. Lett. 285 (1998) 170-173.

[66] J. B. Ott, J. Boerio-Goates, Calculations from Statistical Thermodynamics, Academic Press, 2000.

[67] R. Zhang, B. Dub, G. Sun, Y. Sun, Experimental and theoretical studies on $o^{-}, m^{-}$ and $p$-chlorobenzylideneaminoantipyrines, Spectrochim. Acta A 75 (2010) 11151124.

[68] E.R. Johnson, S. Keinan, P. Mori-Sánchez, J. Contreras-García, A.J. Cohen, W. Yang, Revealing Noncovalent Interactions, J. Am. Chem. Soc. 132 (2010) 6498-6506.

[69] E. Scrocco, J. Tomasi, Electronic Molecular Structure, Reactivity and Intermolecular Forces: An Euristic Interpretation by Means of Electrostatic Molecular Potentials Adv.Quantum.Chem.11 (1978) 115-193.

[70] F. J. Luque, J. M. Lopez, M. Orozco, Perspective on "Electrostatic interactions of a solute with a continuum. A direct utilization of ab initio molecular potentials for the prevision of solvent effects", Theor. Chem. Acc. 103 (2000) 343-345

[71] P. Politzer, J. Murray, The fundamental nature and role of the electrostatic potential in atoms and molecules, Theor. Chem. Acc. 108 (2002) 134-142.

[72] P. Thul, V.P. Gupta, V.J. Ram, P. Tandon, Structural and spectroscopic studies on 2pyranones, Spectrochim. Acta 75 (2010) 251-260 
Table captions

Table 1. Crystal data and experimental parameters used for the intensity data collection strategy and final results of the structure determination.

Table 2. Hydrogen-bonds geometry $\left(\AA{ }^{\circ}{ }^{\circ}\right)$ in $\left(\mathrm{C}_{8} \mathrm{H}_{12} \mathrm{~N}\right)_{2} \mathrm{CrO}_{4}$

Table 3. Optimized structural parameters for the $\left(\mathrm{C}_{8} \mathrm{H}_{12} \mathrm{~N}\right)_{2} \mathrm{CrO}_{4}$ calculated by B3LYP with 6$311++\mathrm{G}(\mathrm{d}-\mathrm{p})$.

Table 4. Calculated absorption wavelength $\lambda$, excitation energies $\mathrm{E}$ and oscillator strengths $f$ for the $\left[\mathbf{C}_{8} \mathbf{H}_{12} \mathbf{N}\right]_{2} \mathbf{C r O}_{4}$ using TD-DFT/B3LYP/6-311++G(d,p) method in DMSO solvent.

Table 5. AIM Analysis of the bond critical points (BCP) for $\left[\mathrm{C}_{8} \mathbf{H}_{12} \mathbf{N}\right]_{2} \mathrm{CrO}_{4}$ compound.

Table 6. Binding energies $(\mathrm{kcal} / \mathrm{mol})$ of known antifungals and $2 \mathrm{PhCr}$ to SAPs from Candida albican.

Table 7. Molecular docking situation of $2 \mathrm{phCr}$ to SAPs fromC. albican along with that of selected antifungals of C. albican. Enzymes are represented as electrostatic potential surface, known antifungals are shown as lines and the $2 \mathrm{phCr}$ is shown as sphere in the first raw. Cluster representation of ligand-enzyme interactions are represented with green color in the second raw. High energetic interactions above $3.5 \mathrm{kcal} / \mathrm{mol}$ are assigned as hydrogen bonding interactions and listed in third raw only for $2 \mathrm{phCr}$.

Table 8. Binding energies $(\mathrm{kcal} / \mathrm{mol})$ of known antibacterial agents and $2 \mathrm{PhCr}$ to $\mathrm{KAS}$ enzymes from E. coli. 
Table 1. Crystal data and experimental parameters used for the intensity data collection strategy and final results of the structure determination.

$\overline{\mathrm{CCDC}}$

Temperature

Empirical formula

Formula weight $\left(\mathrm{g} \mathrm{mol}^{-1}\right)$

Crystal system

Space group

a

$\mathrm{b}$

c

$\beta$

Z

V

$\mathrm{F}(000)$

$\square($ Mo K $\square)$

Index ranges

Reflections collected

Independent reflections

Reflections with $\mathrm{I}>2 \square(\mathrm{I})$

$\mathrm{R}_{\text {int }}$

Absorption correction: multi-scan

Refined parameters

$\mathrm{R}\left[\mathrm{F}^{2}>2 \sigma\left(\mathrm{F}^{2}\right]\right.$

$w R\left(F^{2}\right)$

Goodness of fit

$\Delta \rho_{\max }=0.651 \mathrm{e} \AA^{-3}$
1527549

$150 \mathrm{~K}$

$\left(\mathrm{C}_{8} \mathrm{H}_{12} \mathrm{~N}\right)_{2} \mathrm{CrO}_{4}$

360.37

monoclinic

$C 2 / c$

38.136(2) ^

11.2334(6) $\AA$

8.1643(4) ̊

$98.480(2)^{\circ}$

8

3459.3(3) $\AA^{3}$

1520

$0.682 \mathrm{~mm}^{-1}$

$-49 \leq \mathrm{h} \leq 34,-14 \leq \mathrm{k} \leq 14,-9 \leq 1 \leq 10$

14269

3965

3358

0.0263

$T \min =0.709, T \max =0.921$

232

0.0338

0.0894

1.056

$\Delta \rho_{\min }=-0.318$ e $\AA^{-3}$ 
Table 2. Hydrogen-bonds geometry $\left(\AA,^{\circ}\right)$ in $\left(\mathrm{C}_{8} \mathrm{H}_{12} \mathrm{~N}\right)_{2} \mathrm{CrO}_{4}$

\begin{tabular}{|c|c|c|c|c|}
\hline D-H...A & $\mathbf{D}-\mathbf{H}(\AA)$ & H...A $(\AA)$ & D...A (̊̊) & $\mathbf{D}-\mathbf{H} \ldots \mathbf{. . . A}\left(^{\circ}\right)$ \\
\hline $\mathrm{N} 1-\mathrm{H} 1 \mathrm{~N} 1 \ldots \mathrm{O} 3^{\mathrm{i}}$ & $0.85(2)$ & $1.94(2)$ & $2.757(2)$ & $161(2)$ \\
\hline $\mathrm{N} 1-\mathrm{H} 2 \mathrm{~N} 1 \ldots \mathrm{O} 4^{\mathrm{ii}}$ & $0.84(2)$ & $1.95(3)$ & $2.771(2)$ & $163(2)$ \\
\hline $\mathrm{N} 1-\mathrm{H} 3 \mathrm{~N} 1 \ldots \mathrm{O} 4^{\mathrm{iii}}$ & $0.86(3)$ & $1.90(3)$ & $2.743(2)$ & $167(2)$ \\
\hline $\mathrm{N} 2-\mathrm{H} 1 \mathrm{~N} 2 \ldots \mathrm{O} 4^{\text {iv }}$ & $0.83(3)$ & $2.36(2)$ & $3.012(2)$ & $136(2)$ \\
\hline $\mathrm{N} 2-\mathrm{H} 1 \mathrm{~N} 2 \ldots \mathrm{O} 3^{\text {iv }}$ & $0.83(3)$ & $2.40(2)$ & $2.921(2)$ & $122(2)$ \\
\hline $\mathrm{N} 2-\mathrm{H} 1 \mathrm{~N} 2 \ldots \mathrm{O} 2^{\mathrm{v}}$ & $0.83(3)$ & $2.43(2)$ & $2.992(2)$ & $126(2)$ \\
\hline $\mathrm{N} 2-\mathrm{H} 2 \mathrm{~N} 2 \ldots \mathrm{O} 2$ & $0.93(3)$ & $1.86(3)$ & $2.776(2)$ & $167(2)$ \\
\hline $\mathrm{N} 2-\mathrm{H} 3 \mathrm{~N} 2 \ldots \mathrm{O} 3^{\mathrm{i}}$ & $0.80(3)$ & $1.93(3)$ & $2.726(2)$ & $174(2)$ \\
\hline C10-H10A...O1 & 0.97 & 2.54 & $3382(2)$ & 145.8 \\
\hline
\end{tabular}

Symmetry code :(i) $-x+1 / 2,-y+1 / 2,-z$; (ii) $x,-y+1, z-1 / 2$; (iii) $x, y, z-1$; (iv) $-x+1 / 2, y-1 / 2,-z+1 / 2$; (v) $x,-y$, $z-1 / 2$. 
Table 3. Optimized structural parameters for the $\left(\mathrm{C}_{8} \mathrm{H}_{12} \mathrm{~N}\right)_{2} \mathrm{CrO}_{4}$ calculated by B3LYP with 6$311++\mathrm{G}(\mathrm{d}-\mathrm{p})$.

\begin{tabular}{|c|c|c|}
\hline Parameters & & Exp. \\
\hline \multicolumn{3}{|c|}{ Bond length $(\AA)$} \\
\hline $\mathrm{Cr} 1-\mathrm{O} 2$ & 1.577 & $1.6477(12)$ \\
\hline Cr1-O3 & 1.576 & $1.6774(13)$ \\
\hline Cr1-O4 & 1.732 & $1.6196(13)$ \\
\hline Cr1-O5 & 1.732 & $1.6591(12)$ \\
\hline N6-C14 & 1.478 & $1.472(2)$ \\
\hline N10-C31 & 1.474 & $1.476(2)$ \\
\hline C14-C17 & 1.536 & $1.520(3)$ \\
\hline C17-C20 & 1.513 & $1.503(3)$ \\
\hline $\mathrm{C} 20-\mathrm{C} 21$ & 1.400 & $1.390(3)$ \\
\hline C20-C29 & 1.399 & $1.388(3)$ \\
\hline $\mathrm{C} 21-\mathrm{C} 23$ & 1.394 & $1.385(3)$ \\
\hline $\mathrm{C} 23-\mathrm{C} 25$ & 1.394 & $1.370(3)$ \\
\hline $\mathrm{C} 25-\mathrm{C} 27$ & 1.394 & $1.384(3)$ \\
\hline C27-C29 & 1.394 & $1.382(3)$ \\
\hline C31-C34 & 1.541 & $1.520(3)$ \\
\hline C34-C37 & 1.512 & $1.507(3)$ \\
\hline C37-C38 & 1.400 & $1.390(3)$ \\
\hline C37-C46 & 1.399 & $1.387(3)$ \\
\hline C38-C40 & 1.393 & $1.389(3)$ \\
\hline $\mathrm{C} 40-\mathrm{C} 42$ & 1.394 & $1.379(3)$ \\
\hline $\mathrm{C} 42-\mathrm{C} 44$ & 1.394 & $1.372(4)$ \\
\hline C44-C46 & 1.394 & $1.387(3)$ \\
\hline \multicolumn{3}{|l|}{ RMSD } \\
\hline \multicolumn{3}{|c|}{ Bond angle $\left(^{\circ}\right)$} \\
\hline $\mathrm{O} 2-\mathrm{Cr} 1-\mathrm{O} 3$ & 111.978 & $109.41(6)$ \\
\hline $\mathrm{O} 2-\mathrm{Cr} 1-\mathrm{O} 4$ & 109.808 & $110.12(7)$ \\
\hline $\mathrm{O} 2-\mathrm{Cr} 1-\mathrm{O} 5$ & 107.501 & $112.38(6)$ \\
\hline O2- Cr1-13 & 84.431 & \\
\hline O3- Cr1-O4 & 107.656 & $108.79(7)$ \\
\hline O3- Cr1-O5 & 109.767 & $107.55(6)$ \\
\hline O4- Cr1-O5 & 110.140 & $108.50(7)$ \\
\hline Cr1-O4-N10 & 44.071 & 82.39 \\
\hline Cr1-O5-N10 & 108.495 & 24.36 \\
\hline O4-N10-O5 & 33.386 & 28.45 \\
\hline O4-N10-C31 & 96.574 & 98.56 \\
\hline O5-N10-C31 & 115.000 & 97.35 \\
\hline N6-C14-C17 & 110.846 & $111.56(15)$ \\
\hline C14-C17-C20 & 112.049 & $111.27(16)$ \\
\hline C17-C20-C21 & 120.621 & $120.56(19)$ \\
\hline C17-C20-C29 & 121.008 & $121.40(18)$ \\
\hline C21-C20-C29 & 118.355 & 118.01(19) \\
\hline
\end{tabular}




\begin{tabular}{lcc} 
C20-C21-C23 & 120.925 & $120.9(2)$ \\
C21-C23-C25 & 120.127 & $120.4(2)$ \\
C23-C25-C27 & 119.542 & $119.5(2)$ \\
C25-C27-C29 & 120.116 & $120.3(2)$ \\
C20-C29-C27 & 120.935 & $120.9(2)$ \\
N10-C31-C34 & 114.668 & $109.93(15)$ \\
C31-C34-C37 & 112.494 & $114.03(16)$ \\
C34-C37-C38 & 120.720 & $121.58(18)$ \\
C34-C37-C46 & 120.889 & $120.22(18)$ \\
C38-C37-C46 & 118.363 & $118.19(19)$ \\
C37-C38-C40 & 120.908 & $120.7(2)$ \\
C38-C40-C42 & 120.139 & $120.1(2)$ \\
C40-C42-C44 & 119.546 & $119.7(2)$ \\
C42-C44-C46 & 120.113 & $120.2(2)$ \\
C37-C46-C44 & 120.932 & $121.0(2)$ \\
\hline RMSD & 16.995 & \\
\hline
\end{tabular}


Table 4. Calculated absorption wavelength $\lambda$, excitation energies $\mathrm{E}$ and oscillator strengths $f$ for the $\left[\mathbf{C}_{8} \mathbf{H}_{12} \mathbf{N}_{2} \mathbf{C r O}_{4}\right.$ using TD-DFT/B3LYP/6-311++G(d,p) method in DMSO solvent.

\begin{tabular}{|c|c|c|c|c|}
\hline & \multicolumn{4}{|c|}{ Theoretical } \\
\hline Experimental & $\lambda(\mathrm{nm})$ & $\mathrm{E}(\mathrm{eV})$ & $f(a . u)$ & Major contribution \\
\hline \multirow[t]{13}{*}{439} & 423.2 & 2.93 & 0.0077 & $\mathrm{HOMO} \rightarrow \mathrm{LUMO}(90 \%)$ \\
\hline & 409.4 & 3.03 & 0.0109 & $\mathrm{HOMO} \rightarrow \mathrm{LUMO}+1(90 \%)$ \\
\hline & 406.8 & 3.05 & 0.0002 & HOMO-1 $\rightarrow$ LUMO(97\%) \\
\hline & 394.1 & 3.15 & 0.0009 & HOMO- $1 \rightarrow$ LUMO $+1(98 \%)$ \\
\hline & 381.1 & 3.25 & 0.0025 & HOMO-2 $\rightarrow$ LUMO(74\%) \\
\hline & & & & HOMO-4 $\rightarrow$ LUMO(20\%) \\
\hline & 373.1 & 3.32 & 0.00 & HOMO-3 $\rightarrow$ LUMO (100\%) \\
\hline & 370.3 & 3.35 & 0.0011 & HOMO- $2 \rightarrow$ LUMO+1(58\%) \\
\hline & 366.8 & 3.38 & 0.0070 & HOMO-4 $\rightarrow$ LUMO(51\%) \\
\hline & & & & HOMO-2 $\rightarrow$ LUMO $+1(22 \%)$ \\
\hline & 363.1 & 3.42 & 0.00 & HOMO-3 $\rightarrow$ LUMO+1 (100\%) \\
\hline & 360.2 & 3.44 & 0.0020 & HOMO-6 $\rightarrow$ LUMO(29\%) \\
\hline & & & & HOMO-4 $\rightarrow$ LUMO+1(20\%) \\
\hline \multirow[t]{10}{*}{351} & 351.7 & 3.53 & 0.0071 & HOMO-5 $\rightarrow$ LUMO(38\%) \\
\hline & & & & HOMO-4 $\rightarrow$ LUMO+1(35\%) \\
\hline & 348.2 & 3.56 & 0.0170 & HOMO-5 $\rightarrow$ LUMO(32\%) \\
\hline & & & & HOMO-4 $\rightarrow$ LUMO+1(20\%) \\
\hline & 338.1 & 3.67 & 0.0137 & HOMO-5 $\rightarrow$ LUMO+1(65\%) \\
\hline & 327.5 & 3.79 & 0.0008 & HOMO-7 $\rightarrow$ LUMO+1(60\%) \\
\hline & & & & HOMO-6 $\rightarrow$ LUMO(20\%) \\
\hline & 310.9 & 3.99 & 0.0415 & HOMO-6 $\rightarrow$ LUMO+1(64\%) \\
\hline & 304.1 & 4.08 & 0.0129 & HOMO-7 $\rightarrow$ LUMO(71\%) \\
\hline & 298.4 & 4.16 & 0.0140 & $\mathrm{HOMO} \rightarrow \mathrm{LUMO}+2(90 \%)$ \\
\hline \multirow[t]{16}{*}{292} & 292.3 & 4.24 & 0.0003 & HOMO-8 $\rightarrow$ LUMO(86\%) \\
\hline & 290.3 & 4.27 & 0.0007 & HOMO-1 $\rightarrow$ LUMO+2(98\%) \\
\hline & 277.2 & 447 & 0.0051 & $\begin{array}{l}\text { HOMO- } \rightarrow \text { LUMO }+2(54 \%) \\
\text { HOMO- } 8 \rightarrow \text { LUMO }+1(19 \%)\end{array}$ \\
\hline & 276.0 & 4.49 & 0.0025 & HOMO-8 $\rightarrow$ LUMO+1(49\%) \\
\hline & & & & HOMO-2 $\rightarrow$ LUMO+2(27\%) \\
\hline & 272.8 & 4.55 & 0.0001 & HOMO-3 $\rightarrow$ LUMO+2(100\%) \\
\hline & 269.2 & 4.61 & 0.0131 & HOMO- $4 \rightarrow$ LUMO+2(72\%) \\
\hline & & & & HOMO-2 $\rightarrow$ LUMO+2(19\%) \\
\hline & 262.7 & 4.72 & 0.0053 & HOMO-6 $\rightarrow$ LUMO+2(45\%), \\
\hline & 260.8 & 4.75 & 0.0008 & $\begin{array}{l}\text { HOMO-5 } \rightarrow \text { LUMO+2(20\%) } \\
\text { HOMO-14 } \rightarrow \text { LUMO+1 }(44 \%)\end{array}$ \\
\hline & & & & HOMO-6 $\rightarrow$ LUMO+2(33\%) \\
\hline & 260.2 & 4.76 & 0.0091 & HOMO-5 $\rightarrow$ LUMO+2(59\%) \\
\hline & 256.4 & 4.84 & 0.0100 & HOMO-13 $\rightarrow$ LUMO(35\%) \\
\hline & & & & HOMO-13 $\rightarrow$ LUMO+1(24\%) \\
\hline & 251.6 & 4.93 & 0.0018 & $\mathrm{HOMO} \rightarrow \mathrm{LUMO}+3(77 \%)$ \\
\hline & 250.4 & 4.95 & 0.0045 & HOMO-7 $\rightarrow$ LUMO+2(42\%) \\
\hline
\end{tabular}


Table 5. AIM Analysis of the bond critical points (BCP) for $\left[\mathbf{C}_{8} \mathbf{H}_{12} \mathbf{N}_{2} \mathrm{CrO}_{4}\right.$ compound.

\begin{tabular}{|c|c|c|c|c|c|c|c|}
\hline & O46...H2 & O46...H31 & O46...H23 & H31...H5 & H31...H8 & H11...C32 & H11...C41 \\
\hline $\begin{array}{l}\text { Density of all electrons } \\
\rho(\mathbf{r})\end{array}$ & 0.0216 & 0.0055 & 0.0226 & 0.0026 & 0.0022 & 0.0046 & 0.0045 \\
\hline $\begin{array}{l}\text { Laplacian of electron } \\
\text { density } \nabla^{2} \rho(r)\end{array}$ & 0.1457 & 0.0198 & 0.1555 & 0.0114 & 0.0099 & 0.0149 & 0.0152 \\
\hline $\begin{array}{l}\text { Lagrangian kinetic } \\
\text { energy } G(r)\end{array}$ & 0.0318 & 0.0044 & 0.0339 & 0.0023 & 0.0020 & 0.0031 & 0.0032 \\
\hline Energy density H(r) & 0.0046 & 0.0005 & 0.0050 & 0.0006 & 0.0005 & 0.0006 & 0.0006 \\
\hline $\begin{array}{l}\text { Potential energy } \\
\text { density V(r) }\end{array}$ & -0.0271 & -0.0039 & -0.0289 & -0.0017 & -0.0015 & -0.0026 & -0.0026 \\
\hline $\begin{array}{l}\text { Bond energy } E_{\mathrm{HB}} \\
(\mathrm{kJ} / \mathrm{mol})\end{array}$ & -35.2815 & -5.0455 & -37.5714 & -2.1792 & -2.0123 & -3.3166 & -3.3784 \\
\hline $\begin{array}{l}\text { Electron localization } \\
\text { function (ELF) }\end{array}$ & 0.0223 & 0.0125 & 0.0228 & 0.0037 & 0.0026 & 0.0129 & 0.0122 \\
\hline $\begin{array}{l}\text { Localized orbital } \\
\text { locator (LOL) }\end{array}$ & 0.1312 & 0.1014 & 0.1326 & 0.0573 & 0.0492 & 0.1030 & 0.1005 \\
\hline Ellipticity $(\varepsilon)$ & 0.0352 & 0.5085 & 0.0281 & 0.5553 & 1.2675 & 2.0233 & 5.1480 \\
\hline Eta index $(\xi)$ & 0.1362 & 0.1470 & 0.1365 & 0.1408 & 0.1376 & 0.1483 & 0.1531 \\
\hline
\end{tabular}




\section{ACCEPTED MANUSCRIPT}

Table 6. Binding energies $(\mathrm{kcal} / \mathrm{mol})$ of known antifungals and $2 \mathrm{PhCr}$ to SAPs from Candida albican.

\begin{tabular}{llrrrr}
\hline \multirow{2}{*}{ Antifungal Group } & Inhibitor & IZAP & 2QZW & 2H6S & 2QZX \\
& & SAP & SAP1 & SAP3 & SAP5 \\
\hline \multirow{2}{*}{ Polyenes } & Nystatin & -139.9 & -151.3 & -140.1 & -146.1 \\
& Amphotericin B & -126.7 & -125.5 & -125.8 & -133.6 \\
\hline \multirow{4}{*}{ Azoles } & Posaconazole & -118.1 & -119.2 & -122.6 & -128.1 \\
& Itraconazole & -113.8 & -111.1 & -114 & -116.7 \\
& Ravuconazole & -102.8 & -104.6 & -100.9 & -117.6 \\
& Isavuconazole & -102.8 & -105.2 & -105 & -106.6 \\
& Albaconazole & -100.4 & -94.3 & -101.9 & -97.8 \\
\multirow{2}{*}{ Title molecule } & Voriconazole & -95.6 & -87.6 & -92.2 & -107.3 \\
\hline \multirow{2}{*}{ Antimetabolites } & Fluconazole & -88.4 & -92.3 & -89.7 & -101.2 \\
\hline
\end{tabular}


Table 7. Molecular docking situation of $2 \mathrm{phCr}$ to SAPs fromC. albican along with that of selected antifungals of C. albican. Enzymes are represented as electrostatic potential surface, known antifungals are shown as lines and the $2 \mathrm{phCr}$ is shown as sphere in the first raw. Cluster representation of ligand-enzyme interactions are represented with green color in the second raw. High energetic interactions above $3.5 \mathrm{kcal} / \mathrm{mol}$ are assigned as hydrogen bonding interactions and listed in third raw only for $2 \mathrm{phCr}$.

\begin{tabular}{|l|l|l||}
\hline \multicolumn{1}{|c|}{ SAP } & \\
\hline
\end{tabular}


Table 8. Binding energies $(\mathrm{kcal} / \mathrm{mol})$ of known antibacterial agents and $2 \mathrm{PhCr}$ to $\mathrm{KAS}$ enzymes from E. coli.

\begin{tabular}{llll}
\hline Compounds & 2VB9 & 4LS5 & 3iL9 \\
& FabB & FabF & FabH \\
\hline $2 \mathrm{PhCr}$ & -92.8 & -88.4 & -101 \\
Aminothiazole & -99.9 & -83 & -99.8 \\
Cerulerin & -91.2 & -81.8 & -85.1 \\
Thilactomycin & -78.1 & -67.7 & -71.4 \\
\hline
\end{tabular}




\section{Figure captions}

Figure 1. ORTEP drawing of $\left(\mathbf{C}_{8} \mathbf{H}_{12} \mathbf{N}\right)_{2} \mathbf{C r O}_{4}$ with the atom-labeling scheme. Displacement ellipsoids are drawn at the $45 \%$ probability level. $\mathrm{H}$ atoms are represented as small spheres of arbitrary radii.

Figure 2. Projection of $\left(\mathrm{C}_{8} \mathbf{H}_{12} \mathbf{N}\right)_{2} \mathrm{CrO}_{4}$ structure along the $b$ axis.

Figure 3. Hirshfeld surfaces mapped with dnorm.

Figure 4. Two-dimensional fingerprint plots of O..H, H... , O..O, C...H, H...C and H...H intermolecular.

Figure 5. Solution state UV/vis spectra of $\left(\mathrm{C}_{8} \mathrm{H}_{12} \mathbf{N}\right)_{2} \mathrm{CrO}_{4}$ (a) and determination of the energy gap (b) according to the Tauc model.

Figure 6. The frontier molecular orbitals of $\left(\mathrm{C}_{8} \mathbf{H}_{12} \mathbf{N}\right)_{2} \mathrm{CrO}_{4}$ computed with TDDFT(B3LYP)/6-311++G(d,p) in gas phase.

Figure 7. DTA and TG curves of $\left(\mathrm{C}_{8} \mathrm{H}_{12} \mathbf{N}\right)_{2} \mathrm{CrO}_{4}$ at rising temperature.

Figure 8. AIM molecular graph showing the different bond critical points (BCPs) of $\left(\mathrm{C}_{8} \mathbf{H}_{12} \mathbf{N}\right)_{2} \mathbf{C r O}_{4}$ calculated with B3LYP/6- 311++G(d,p) level. The BCPs are denoted as red smaller balls.

Figure 9. Plots of the RDG versus the electron density $\rho$ multiplied by the sign of $\lambda_{2}$ for $\left(\mathrm{C}_{8} \mathrm{H}_{12} \mathrm{~N}\right)_{2} \mathrm{CrO}_{4}$ structure (a), Color scaling of weak interactions. The surfaces are colored on a blue-green-red scale according to values of sign $\lambda_{2}$. Blue indicates strong attractive interactions and red indicates strong non-bonded overlap (b).

Figure 10. The total electron density mapped with electrostatic potential surface of $\left(\mathbf{C}_{8} \mathbf{H}_{12} \mathbf{N}\right)_{2} \mathbf{C r O}_{4}$ calculated at B3LYP/6-311++G(d,p) level. 


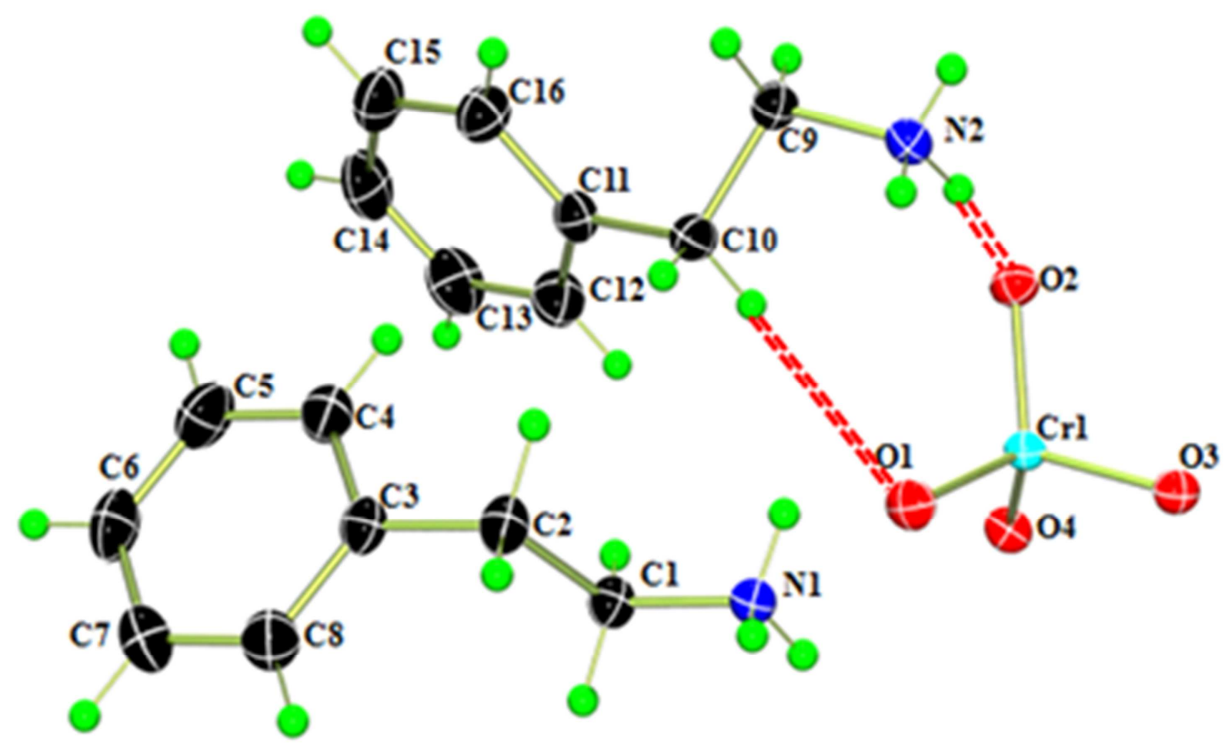

Figure 1. 


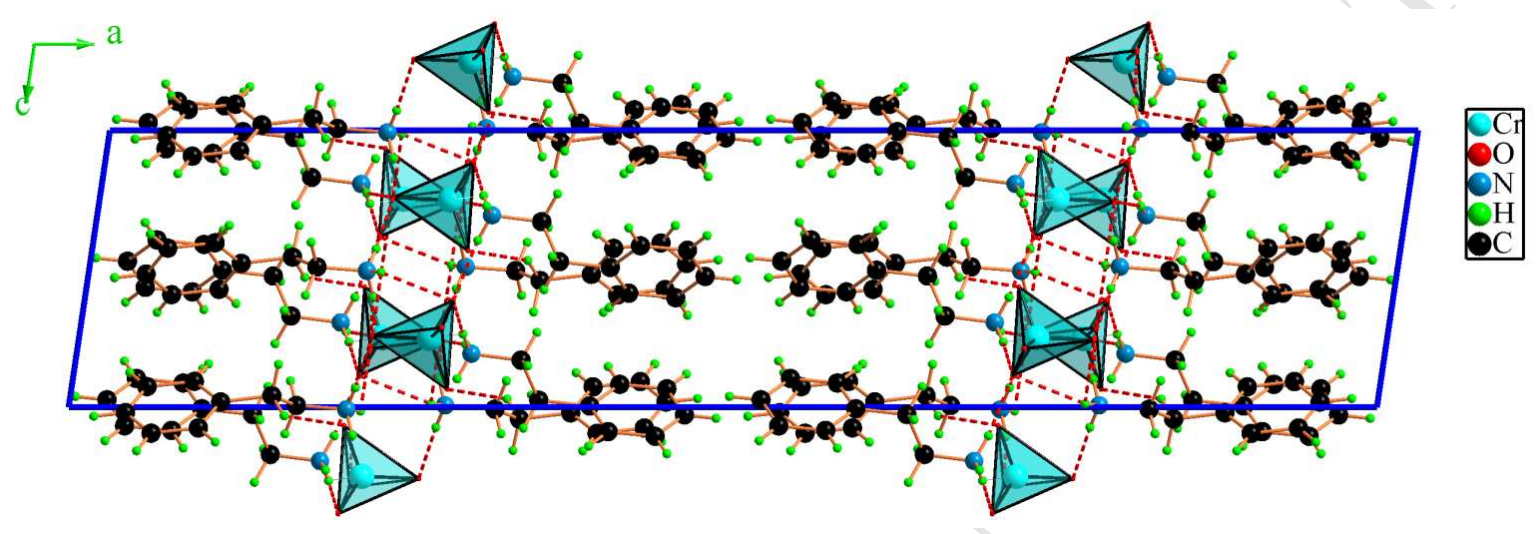

Figure 2 


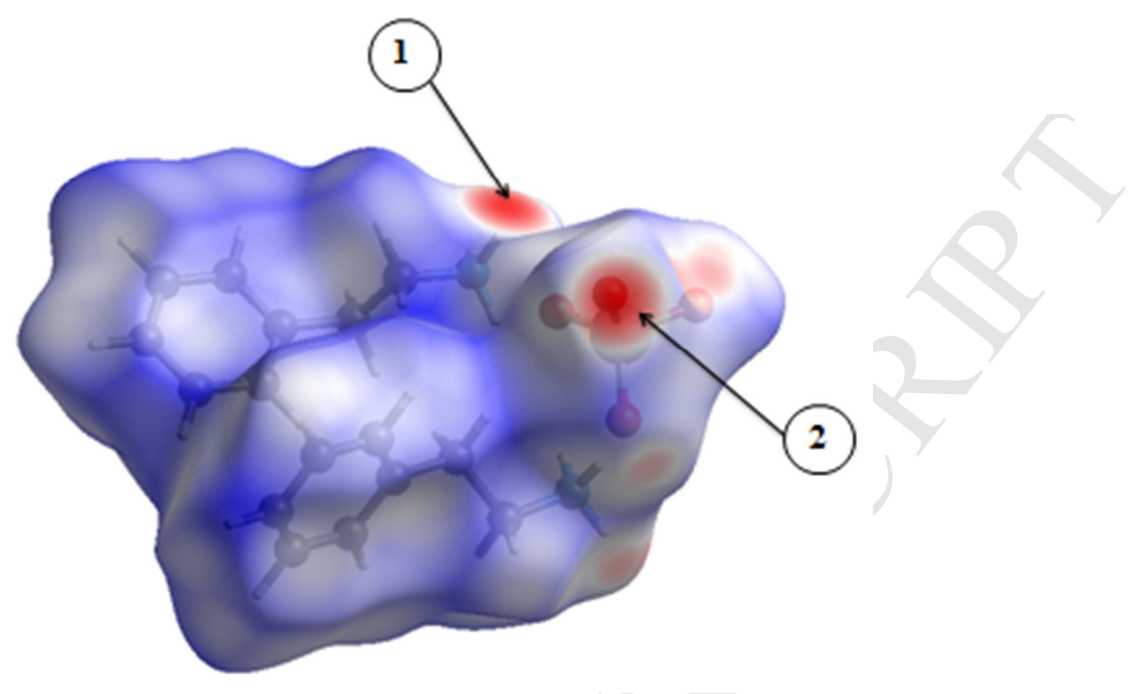

Figure 3 

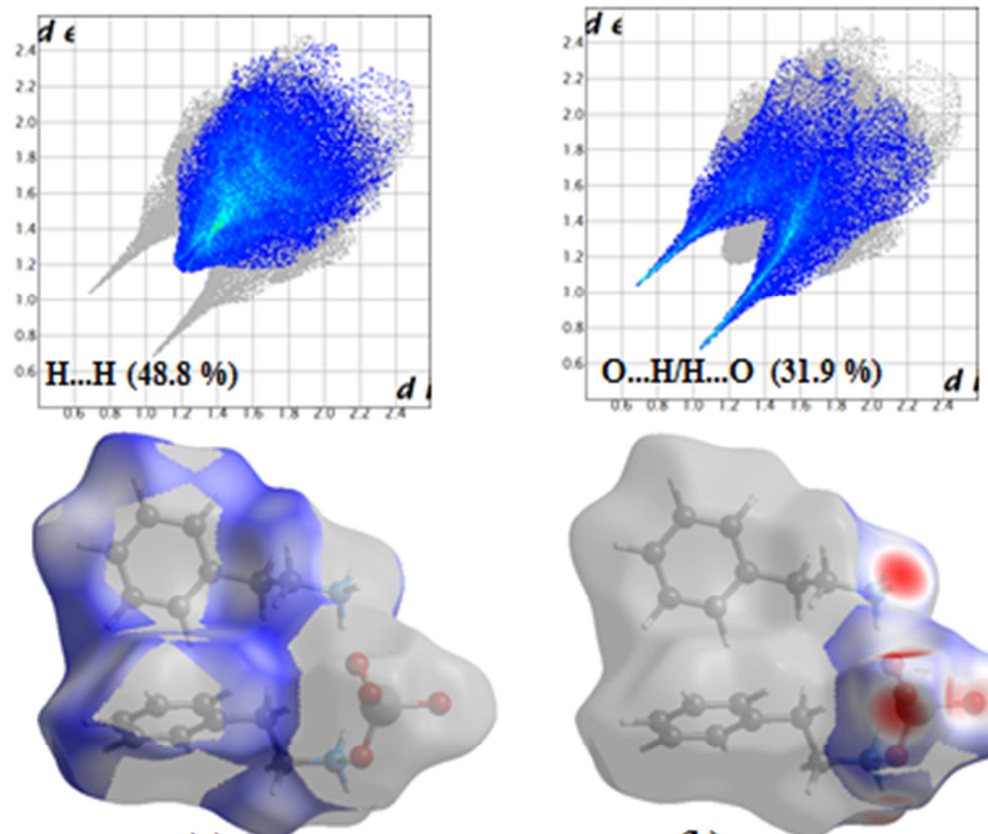

(a)

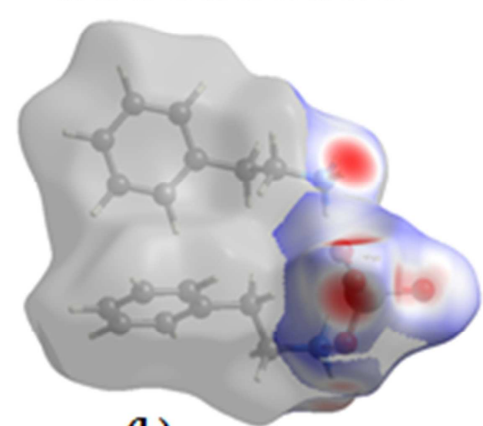

(b)
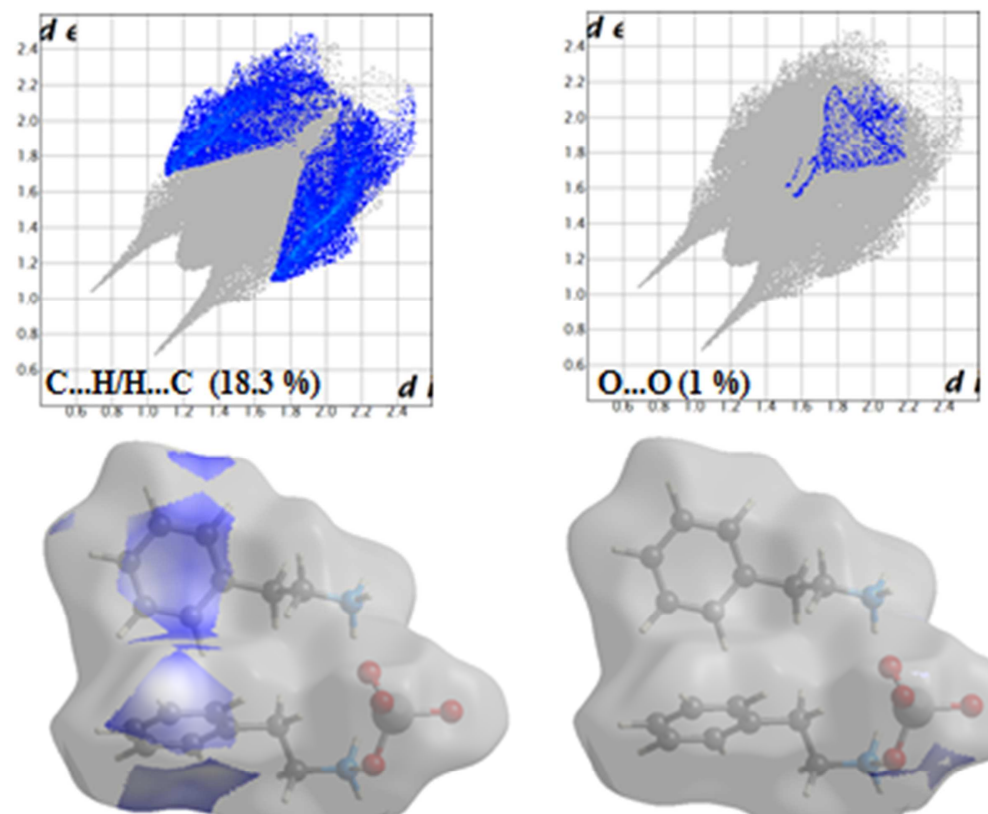

(c)

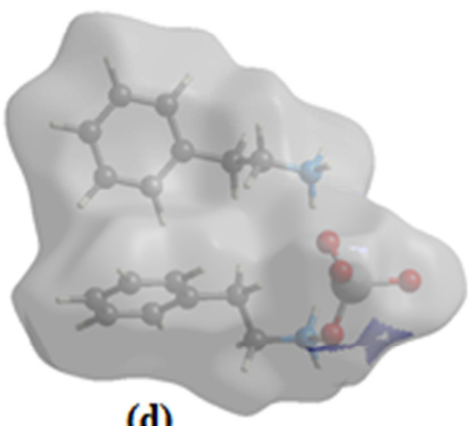

(d)

Figure 4 

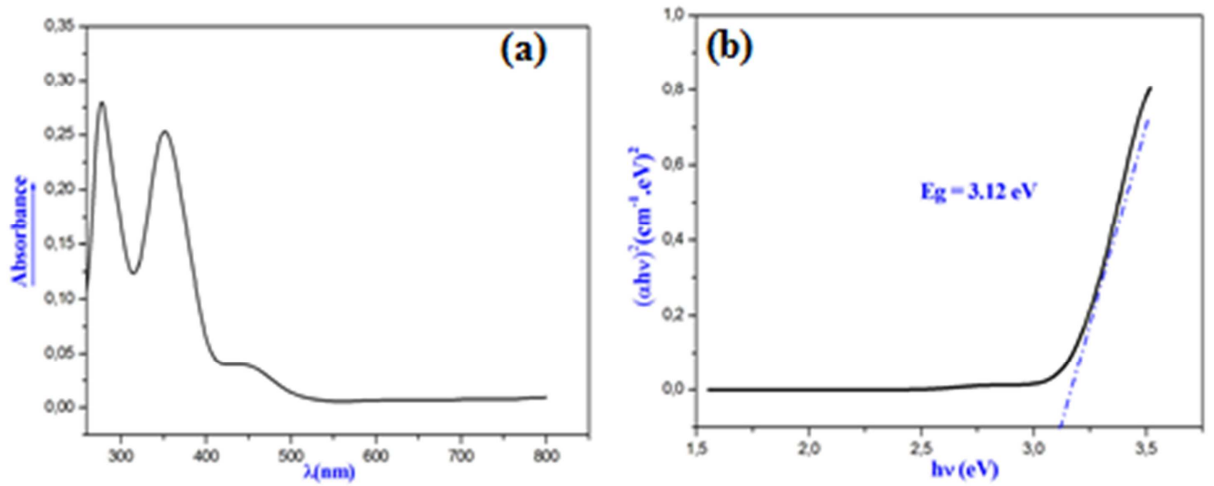

Figure 5 

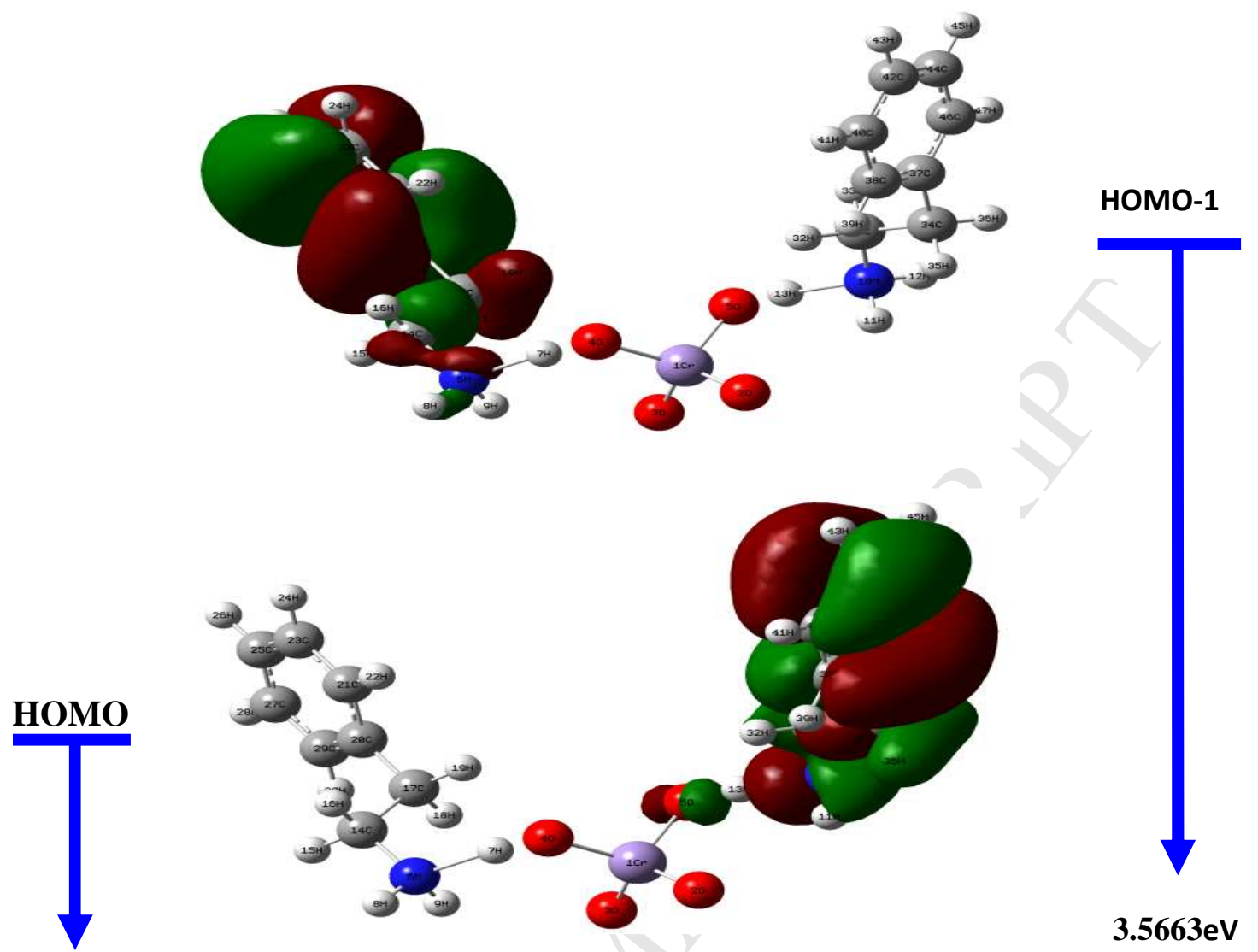

3.5663eV
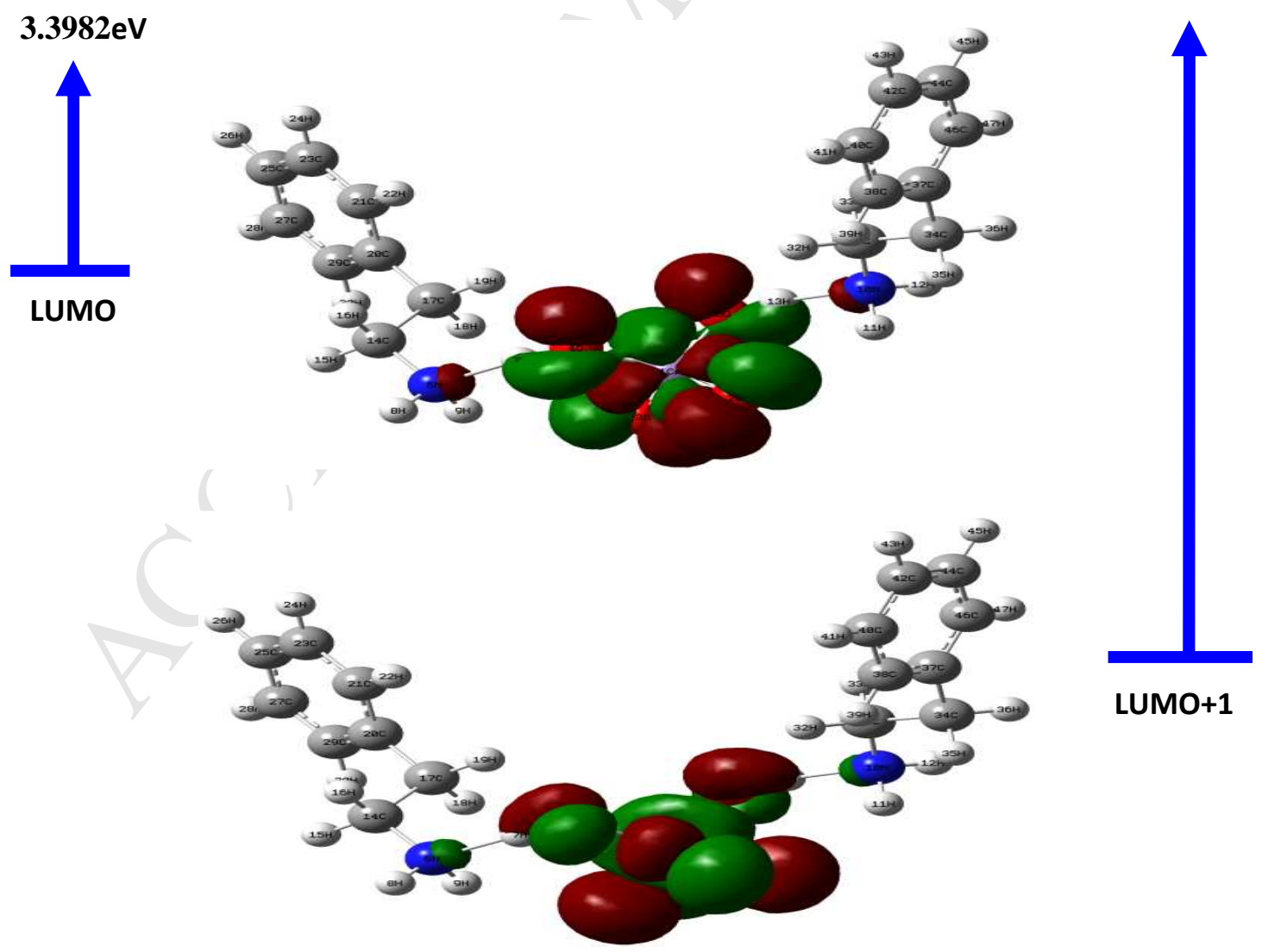

Figure 6 


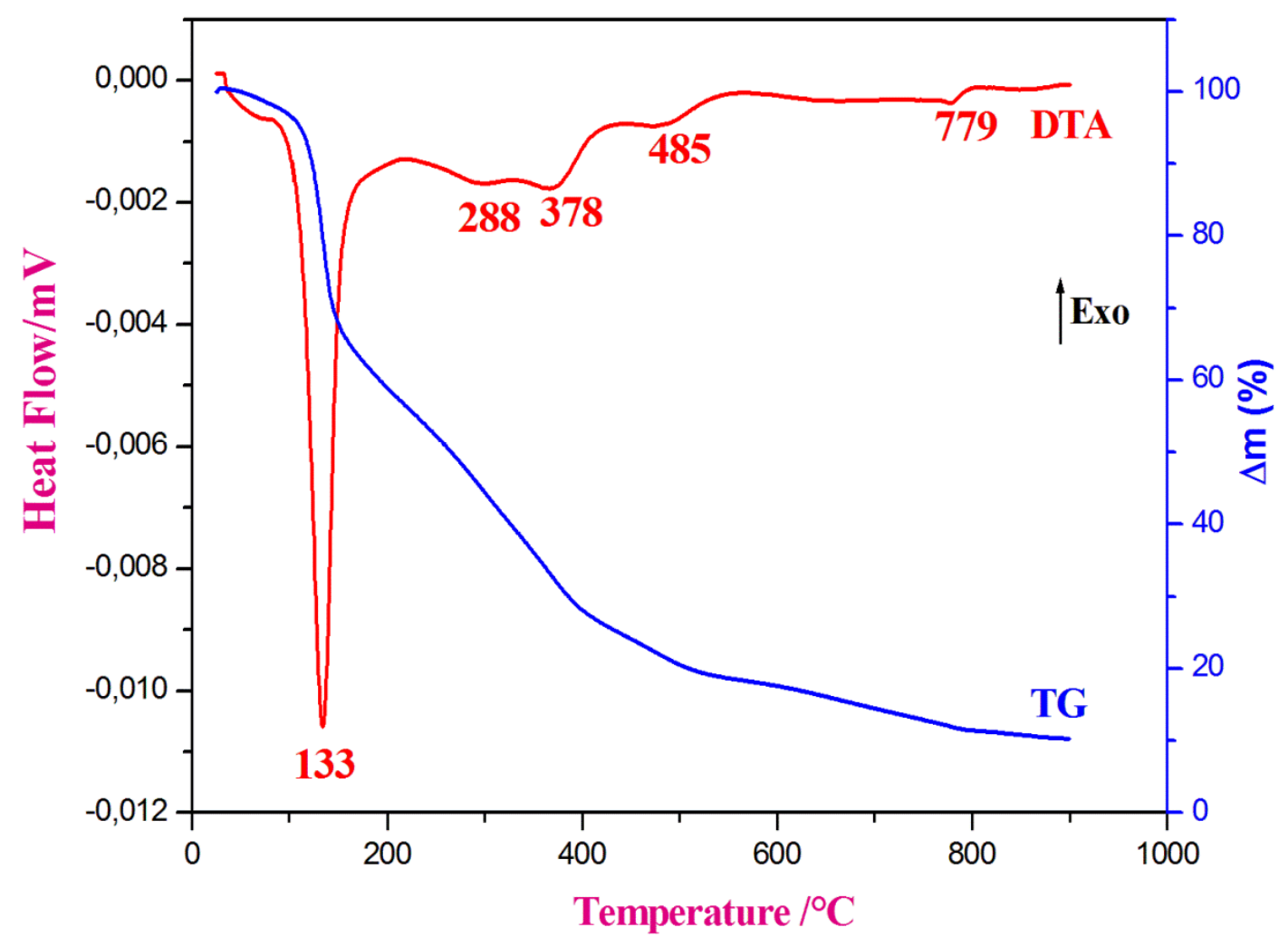

Figure 7 


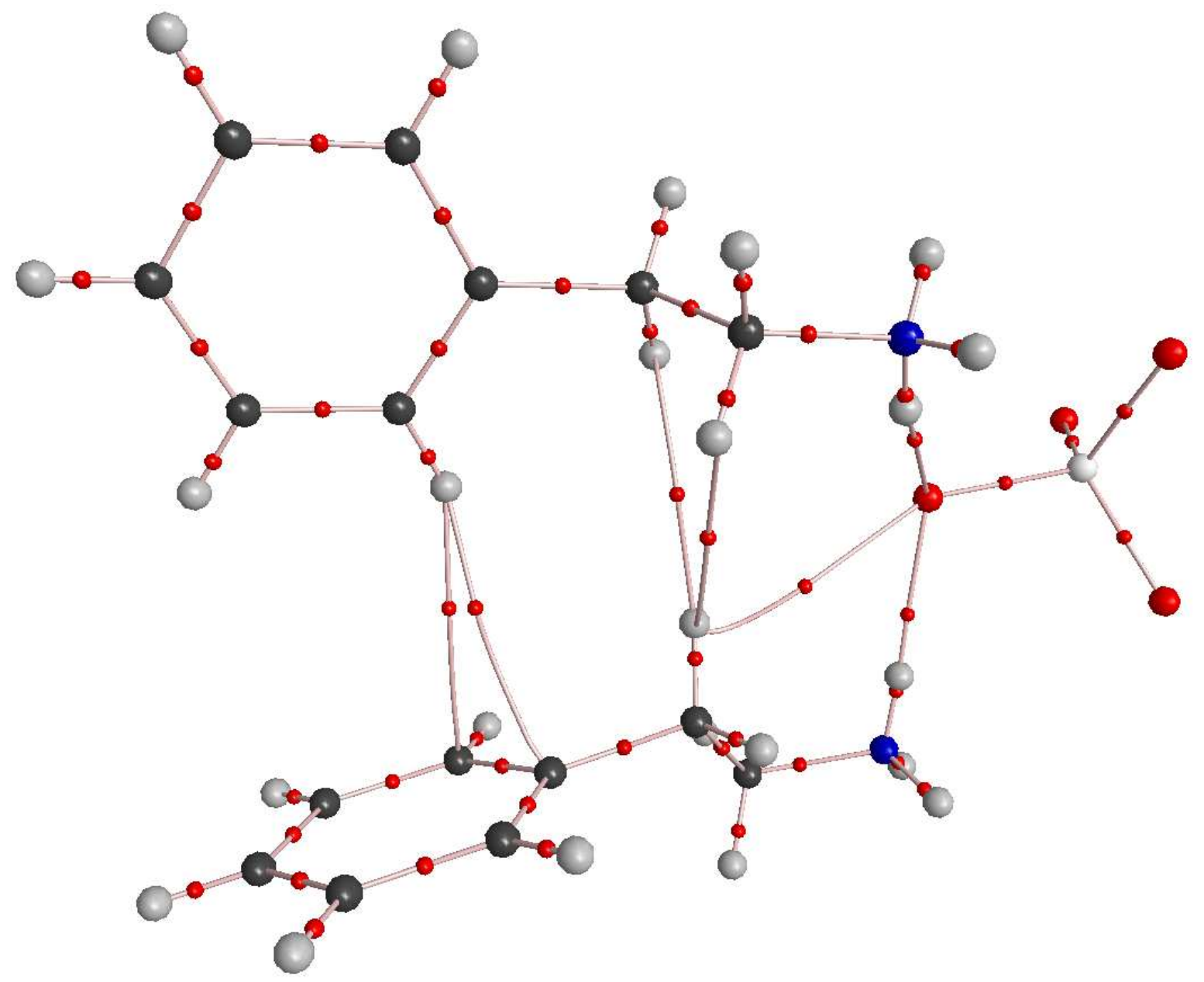

Figure 8 
(a)

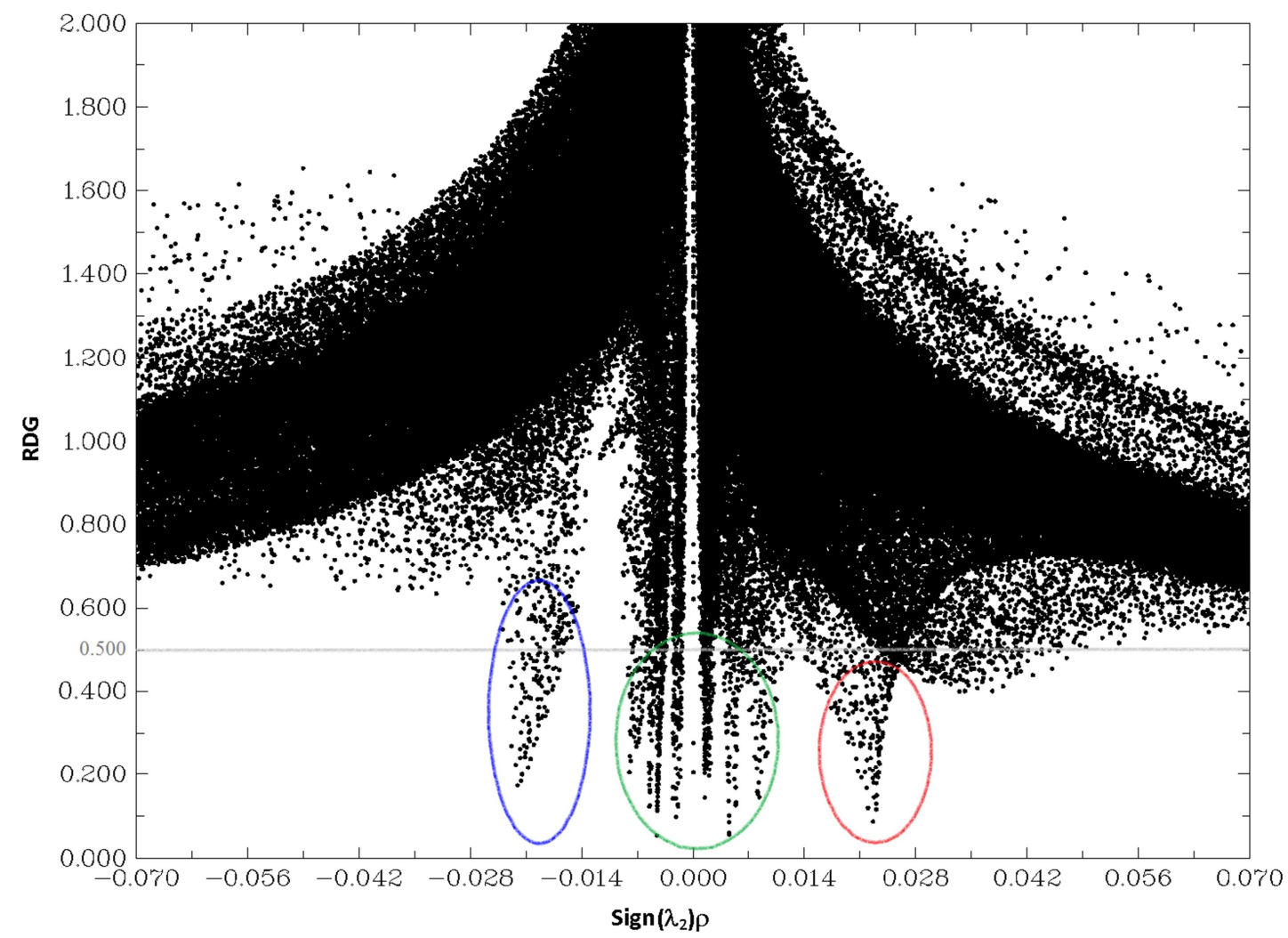

(b)

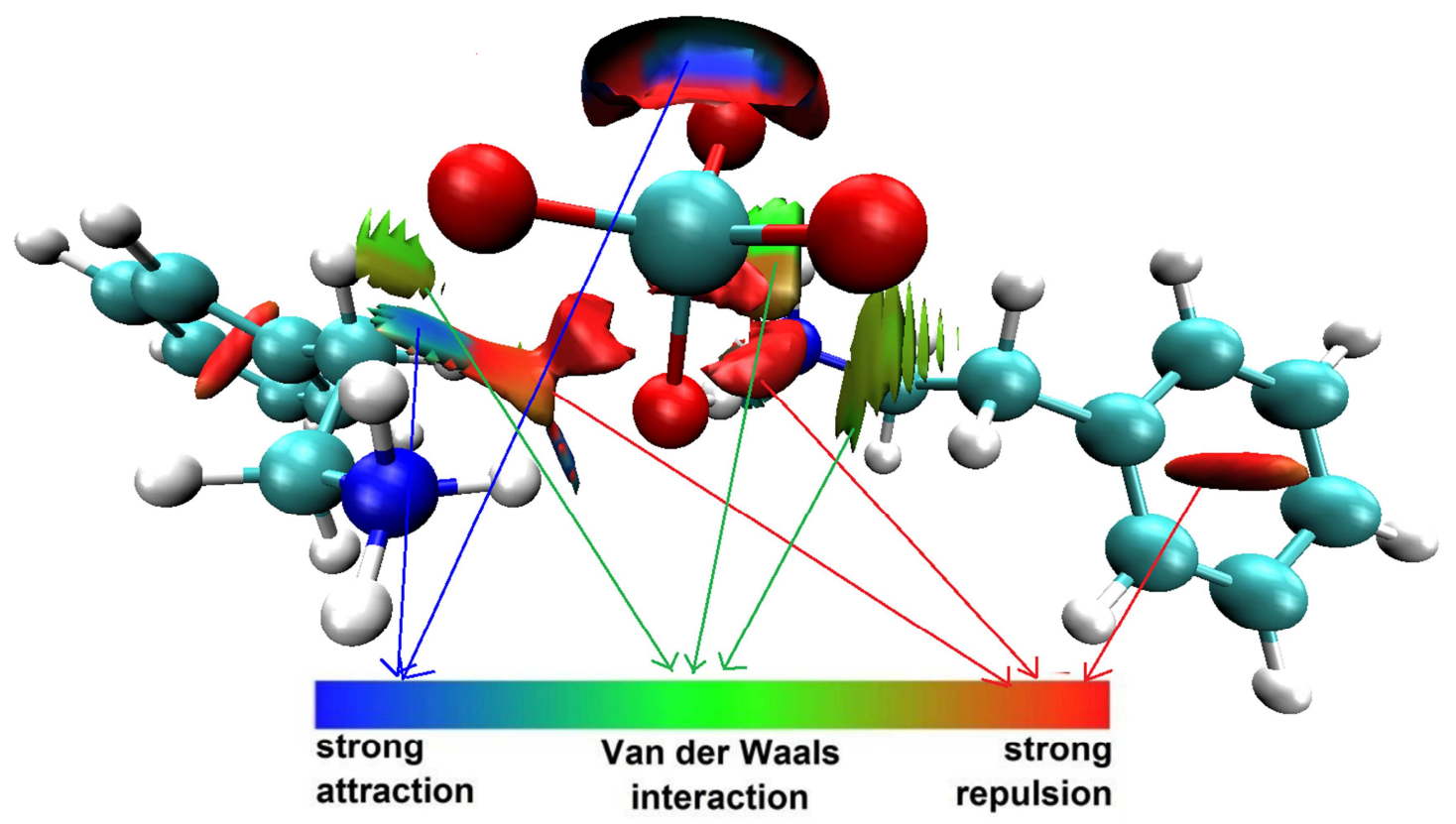

Figure 9 


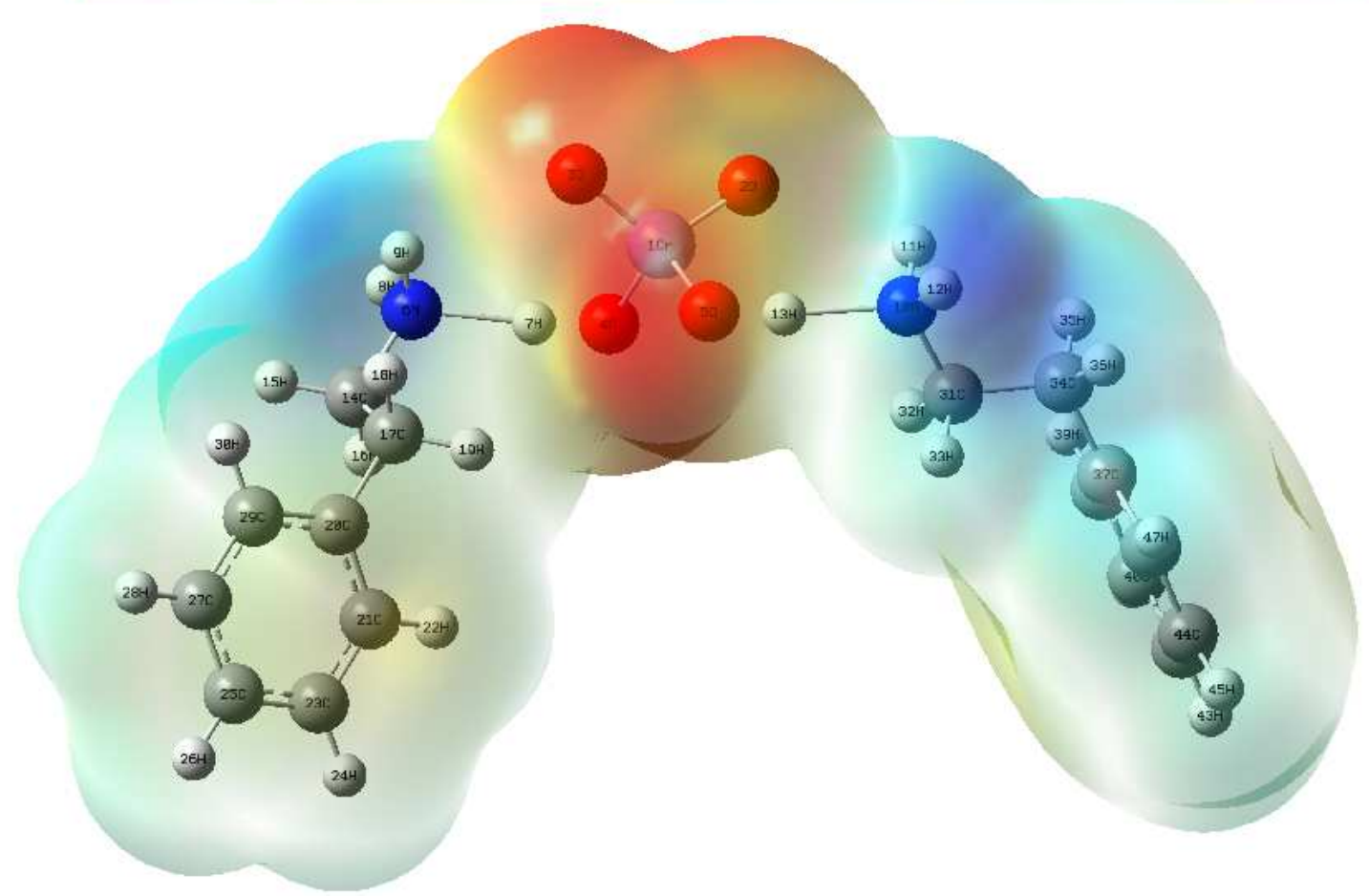

Figure 10 


\section{Highlights}

- A new organic-inorganic complex was prepared at room temperature.

- The atomic arrangement of the synthesized compound shows 2D network.

- The intermolecular interactions were analyzed by Hirshfeld surfaces.

- Antibacterial activities against 5 pathogenic and antifungal activities are presented. 